\title{
3 Writing from Left to Right
}

Partially overlapping with manuscripts written by students are those that contain examples of text reading from left to right. Before the twentieth century, Chinese text usually read in vertical columns from right to left. This direction is present in the earliest examples of Chinese characters on bone and bronze and thus forms a tradition of more than three thousand years. ${ }^{315}$ There are, however, occasional examples of oracle-bone and bronze inscriptions that read in a different direction, but on the whole the direction of writing remained unchanged until very recently. Among the few exceptions to this pattern are several groups of manuscripts and inscriptions found in Dunhuang, featuring Chinese text written from left to right. Such examples are, as the other phenomena presented thus far, limited to the Guiyijun period. This paper divides such cases into two typologically different groups and examines each of them separately. My argument is that the unconventional direction of writing reflects the influence of non-Chinese scribal cultures which had a tradition of writing in a different direction. As a consequence, the examination of such manuscripts and inscriptions has implications for understanding the cultural affinities of manuscript groups. Just as importantly, determining the exact chronological framework of such cases helps to date undated manuscripts and paintings.

The modern practice of writing Chinese characters horizontally began during the late nineteenth and early twentieth century, largely due to the influence of Western scientific literature and language-learning material. ${ }^{316}$ Among the early publications was the Chinese translation of Edwin J. Houston and Arthur E. Kennelly's Algebra Made Easy, which appeared in China under the title Suanshi jiefa 算式 解法 only a year after its 1898 American release. ${ }^{317}$ Other books related to language teaching, such as the 1904 Yingwen Hangu 英文漢詁 (English title: English Grammar Explained in Chinese) by Julin Khedau Yen-Fuh (Yan Fu 嚴复), featured an extensive amount of horizontal Chinese text interspersed with English sample sentences. Far earlier than this, as Zhang Zhiqiang 張志強 pointed out, Robert Morrison's (17821834) early nineteenth-century Dictionary of the Chinese Language had already printed Chinese characters horizontally in a left-to-right direction. ${ }^{318}$

315 See, for example, Matsumaru 1980, 66-67, 89-90 and 134. For an example of sequential oracle-bone divinations written from left to right, see Takashima 2000, 394.

316 This episode in the development of Chinese written culture is surprisingly under-studied. Among the few scholarly contributions is Zhang Zhiqiang 1997.

317 Hao and Kai 1899.

318 Zhang Zhiqiang 1997, 68, Morrison 1815-1823.

๖ Open Access. ๑ 2020 Imre Galambos, published by De Gruyter. (G) Br-Nc-ND This work is licensed under the Creative Commons Attribution-NonCommercial-NoDerivatives 4.0 International License. 
Anglophone Protestant missionaries, however, were clearly not the inventors of this practice, as evidenced by examples in manuscripts and printed books in other European languages, such as French, Latin and Portuguese. ${ }^{319}$ But in the majority of these examples the Chinese characters had been incorporated into the horizontal lines of the Latin script, rather than being written on their own as continuous text. Monolingual Chinese and Japanese books written entirely horizontally appeared in the twentieth century and increased in popularity only gradually. In mainland China, the left-to-right horizontal direction of writing was officially introduced in $1956 .{ }^{320}$ Yet even today many books follow the traditional alignment of vertical lines. Most newspapers combine vertical and horizontal sections and titles as a means for creating a more interesting layout. Nonetheless, it would be a mistake to see the shift to horizontal writing as a one-way development. Frequently, when aspects of writing considered traditional (e.g. vertical columns, nonsimplified characters and traditional-style punctuation) are used, these efforts are meant to emphasise a link with traditional culture.

It is crucial to note here that directionality is an attribute of the script, not the language. Over its long history, the Chinese language has been, and to some extent still is, written in different scripts, each having its own direction. The Dunhuang manuscripts include examples of continuous Chinese text written with the Tibetan alphabet in horizontal lines running from left to right. ${ }^{321}$ During the Mongol period, the 'Phags-pa script was sometimes used to write Chinese in vertical columns from left to right. ${ }^{322}$ The Muslim Hui have been using, alongside Chinese characters, the Arabic script (i.e. xiaojing 小經 or xiaoerjing 小兒經), which reads horizontally from right to left. ${ }^{323}$ These are not isolated cases or occasional renderings of individual words or phrases but entire sub-cultures in which the

319 One such example is the French Jesuit missionary Cibot's (1727-1780) letter on the Chinese script, which includes a few examples of Chinese text that read horizontally, from left to right; see Pierre-Martial Cibot, Lettre de Pékin, sur le génie de la langue chinoise et la nature de leur écriture symbolique, comparée avec celle des anciens Égyptiens, published in 1773. Manuscripts examples with Chinese text written horizontally from left to right go back as far as the Portuguese-Chinese glossary by Michele Ruggieri (1543-1607) and Matteo Ricci (1552-1610); see Witek, Ruggieri and Ricci 2001.

320 Wiedenhof 2015, 365-366.

321 Simon 1958, Takata 1993 and 2000, 58-59. The same direction of writing is also attested among the Dungans, who use the Cyrillic (and earlier the Latin) alphabet to write a northwestern Chinese dialect; Rimsky-Korsakoff 1967, 357-364 and Mair 1990.

322 Coblin 2007, 1-22.

323 Zavyalova 1999, Sobieroj 2014 and 2019. 
sounds of the Chinese language are recorded with a phonetic script in a direction that differs from the way Chinese characters normally read.

The existence of left-to-right examples of Chinese text in Dunhuang manuscripts and paintings was noted already at the initial examination of the contents of the Dunhuang library cave. Paul Pelliot, who came to the Mogao Caves shortly after Aurel Stein, was the first to note this phenomenon while looking through the manuscripts at the site. In a letter written to the Indologist Émile Senart (18471928) on 26 March 1908, within days after going through the contents of the cave, Pelliot mentioned that some of the Chinese pothi manuscripts were written horizontally, from left to right, 'just like we print Chinese in our European books'.324 Pelliot's diary entries written during his visit to Dunhuang also record his surprise at seeing Chinese written in this anomalous direction. Interestingly, there seems to have been no interest in examining the cultural ramifications of writing horizontally on pothi manuscripts since Pelliot's comments. ${ }^{325}$

Many later studies mention the left-to-right direction of writing, but these are all cases of Chinese characters that read in vertical columns, and an entirely different category from those Pelliot commented upon. In his catalogue of the British collection of Chinese manuscripts, Lionel Giles made an effort to document this practice but many examples escaped his attention, partly because they were too fragmentary. ${ }^{326}$ The catalogue of the French collection also recorded such cases, including a list of relevant manuscripts for a convenient overview. ${ }^{327}$ The phenomenon has been noted even more commonly in connection to paintings. In his 1931 catalogue of Dunhuang paintings acquired by Aurel Stein, for instance, Arthur Waley remarked that some of the inscriptions read from left to right. ${ }^{328}$ In a study on the Maitreya's Paradise painting of the Fogg Art Museum, Rei Sasaguchi stated that '[I]nscriptions written from left to right are not uncommon among the paintings and manuscripts recovered from Tun-huang. ${ }^{329}$ Similarly, in his cata-

324 Quoted in Drège and Moretti 2014, 4. Later this comment became part of Pelliot's initial report on the acquisition of Dunhuang manuscripts; Pelliot 1908, 509.

325 Ghesquière and Macouin 2008, 68. In one place (ibid., 312) he accidentally mentions the direction as running from right to left but it is clear that he means the opposite direction, especially as he adds that this direction is the same as the one in European printed works.

326 E.g. Giles 1957, 53 and 158.

327 The first volume of the catalogue (Gernet and Wu 1970) appeared only in 1970, even though it was already completed in 1955. This first volume only listed manuscript P.2473 in the index, missing P.2439 which also has an example of a left-to-right bit of text on the verso.

328 Waley 1931.

329 Sasaguchi 1972/1973, 46. 
logue of Stein paintings at the British Museum, Roderick Whitfield carefully made note of all such instances. ${ }^{330}$

Despite such references to an otherwise uncommon way of writing Chinese, scholarship has paid little attention to the phenomenon until relatively recently. Part of the reason for this was that in most cases the unorthodox writing direction presented no challenge for reading the inscriptions and thus generated no interest to wrestle with the topic at a deeper level. Among the few brief studies on the subject is a paper by Yang Sen 楊森, who connected the examples from Dunhuang with other cases from early and medieval China, arguing that this manner of writing, unusual as it was, has been an inherent part of Chinese written culture throughout its history. ${ }^{331}$ While this view is certainly not incorrect, comparing examples as diverse as Shang oracle-bone inscriptions, Zhou bronze inscriptions and Dunhuang paintings generates an overly broad time frame, concealing the cultural background of the practice in Guiyijun Dunhuang. Yang correctly hypothesised that rather than being invented in Dunhuang, this way of writing must have originated elsewhere, in spite of the fact that he was referring to earlier cases in the Chinese tradition.

Another recent paper on the subject is by Zhu Yao 朱瑤, who divided the examples of left-to-right writing into three categories. The first being manuscript colophons; the second, inscriptions on Buddhist paintings; and the third, contracts and circulars copied on the verso of scrolls. She suggested that this practice must have been linked to the cultural background of the period in question. She considered its origins to be related to Dunhuang's location on the Silk Road and the interaction with peoples who wrote their languages in a different direction. In particular, she saw the involvement of the Chinese population in Tibetan sutra-copying enterprises during the Tibetan period as the direct motivation for writing in this manner. Simultaneously, Zhu Yao drew attention to the symmetrical arrangement of inscriptions, furnishing examples in which the unconventional direction of writing could be attributed to the symmetry of the design. In terms of the time frame of the phenomenon, she believed that it had begun during the Tibetan period but persisted, as a remnant of that era, into the Guiyijun period. ${ }^{332}$ This chapter is to demonstrate, however, that examples of this practice invariably date to the Guiyijun period. ${ }^{333}$

330 Whitfield 1982-1985.

331 Yang Sen 2001.

332 Zhu Yao 2011.

333 Cf. Galambos 2012, 79-84 and Galambos 2015a, 868-871. 
This chapter explores the topic in a systematic manner, by examining a larger pool of examples, to attain a more reliable understanding of the phenomenon. Similarly, close attention to the relevant dates in the manuscripts and paintings allows to demarcate the chronological dimension of the practice, which is vital in interpreting its cultural background. As will be seen below, the examples narrow down the overall time frame of the phenomenon, connecting it expressly with the Guiyijun period. Typologically, examples of Chinese left-toright writing at Dunhuang are of two distinct types, depending on whether the text reads (1) horizontally or (2) vertically. Specimens of horizontal lines occur in pothis and can be linked directly to Tibetan manuscript culture. The second type featuring vertical lines of text is more common and can be divided further into three subtypes in terms of where and in what context the texts appear. They may be part of (i) the geometrical compositions in manuscripts with mandalas and dhāraṇi-amulets; (ii) the miscellaneous and seemingly random content on the margins and verso of manuscripts; (iii) the cartouches and donor inscriptions in votive paintings on silk, canvas and paper. I believe that we can attribute the development of all types and subtypes to the influence of non-Chinese scribal cultures, although the very sources of such influence may vary.

\subsection{Horizontal lines on pothi leaves}

Among the manuscripts from Dunhuang are a couple of pothi-leaf manuscripts with Chinese characters written horizontally, in a left to right direction. These must be the same items Pelliot described in his letter to Émile Senart. In addition, there are also pothi leaves with folio numbers written in this direction. The pothi form itself indicates a link to Tibetan manuscript culture, which is therefore the source of influence.

As seen in Chapter One, the pothi form ultimately derives from the Indian palm-leaf manuscript, yet in Dunhuang it reflects the influence of Tibetan scribal culture. Tibetan texts are written on the leaves horizontally, in a left-to-right direction. Typically, a single leaf has five to seven horizontal lines of text. But when scribes adopt pothi leaves for writing Chinese, they rotate them 90 degrees and write the text in long vertical columns, often with the help of ruling lines. It is such pothis that contain cases of Chinese text written horizontally from left to right, emulating the arrangement of Tibetan manuscripts. This coincides with the way in which Chinese is usually written today, a practice which is similarly the result of influence from the West. In both cases innovation came from outside as a result of interaction with cultures using an alphabetic or syllabic script. 
As a result of not using a string to bind the leaves together and stabilise their order, some pothis have folio numbers. This device was unnecessary when writing on scrolls, but became a feature of new manuscripts forms, such as the pothi and the codex. Interestingly, the folio numbers on pothi leaves are sometimes not rotated along with the Chinese text but maintain the orientation of Tibetan manuscripts. For instance, P.3914 (Fig. 34), a collection of Tantric texts and spells, is a manuscript with folio numbers going up to 30, appearing consistently at 90 degrees in relation to the main text. ${ }^{334}$ This is a carefully executed manuscript which occasionally uses red ink for titles and key Buddhist terms, indicating that the orientation of folio numbers was not random but formed part of a deliberate design adhered to throughout the entire manuscript. ${ }^{335}$

334 The phenomenon of Chinese folio numbers being added at 90 degrees in relation to the non-Chinese main text is also found in Uighur manuscripts and printed texts from Turfan. For example, in U 4727, an Uighur fragment of a printed concertina volume from the Berlin Turfan Collection, the Chinese folio number is at a 90 degree rotation to the main text, which runs vertically from left to right; cf. Yakup 2009, 187-188. In other cases, e.g. U 0374, folio numbers appear to follow the orientation of the Uighur text.

335 The use of red ink is, however, not consistent as words in red disappear from the later part of the manuscript. The red ink appears to have two main functions, the first of which is to segment the text and make it easier to read. The other function, apparent in Fig. 34, is to mark Buddhist terms that command respect. 


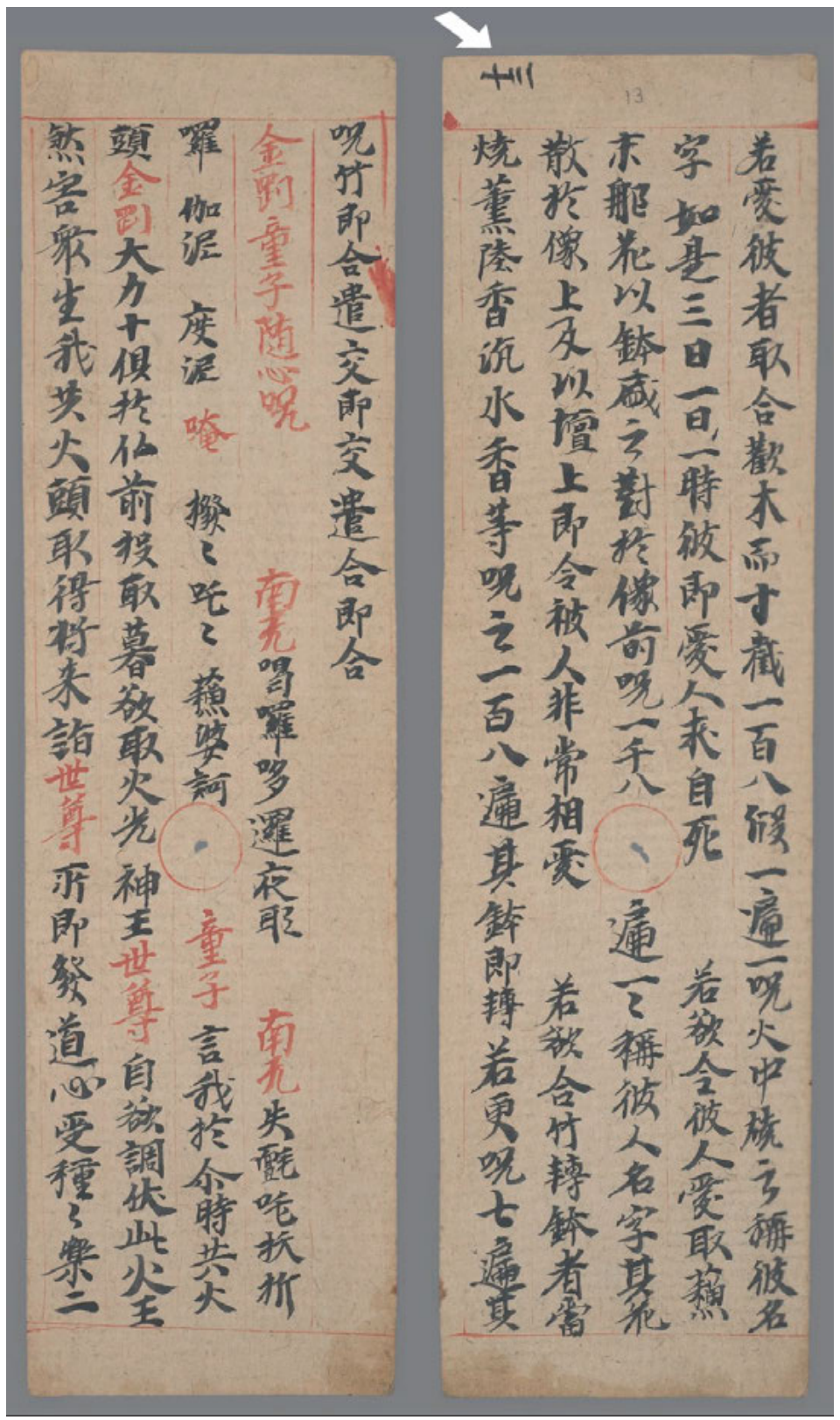

Fig. 34: Chinese manuscript in a pothi form, P.3914; the folio number 13, marked by the white arrow, is at 90 degrees to the main text. $(27 \times 7.5 \mathrm{~cm}$; Bibliothèque nationale de France $)$ 
An interesting case is manuscript P.3920, in which the folio numbers follow the orientation of the main text, making them easily legible when holding the pothi leaves vertically. Once the numbers reach 11 十一 so that they consist of more than one character, the two constituent characters are written vertically, following the usual way of writing Chinese. Yet from folio 24 廿四 until folio 101 一百一 the numbers are written horizontally, from left to right (Fig. 35). The sole exception is folio $41 \mathrm{HI}$ 一, which reads vertically, whereas all other folio numbers around it have a horizontal orientation.

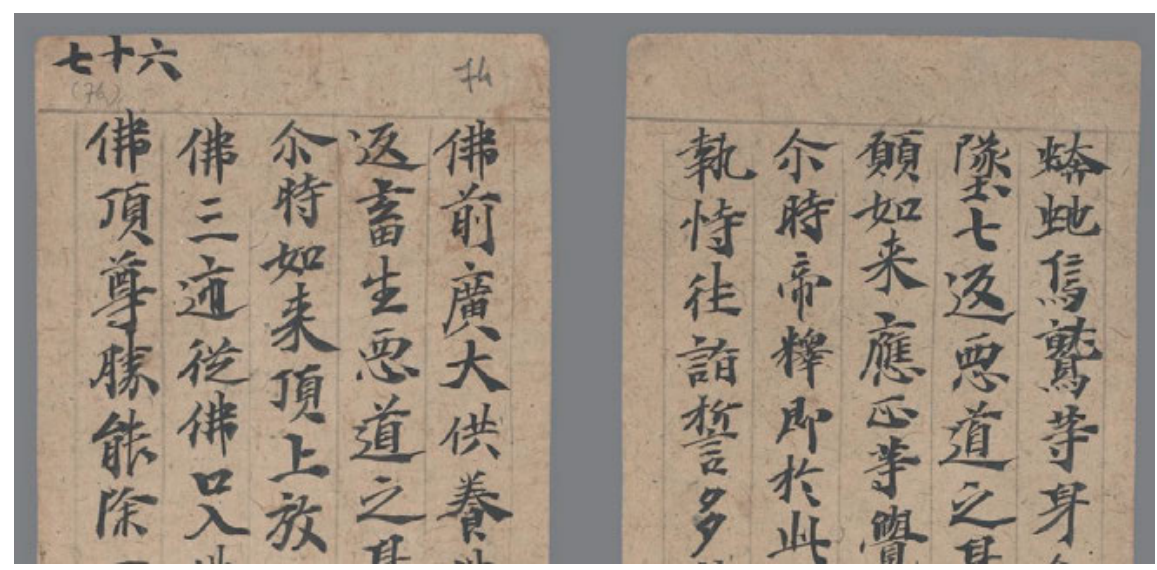

Fig. 35: Horizontal folio number 76 in manuscript P.3920. $(28.8 \times 8.4 \mathrm{~cm}$; Bibliothèque nationale de France)

Yet another example is manuscript P.3916, in which the direction of folio numbers is inconsistent from one folio to the other (Fig. 36). The orientation of numbers matches that of the main text, assuming a vertical reading of the leaves. When there are only two characters (e.g. 11 十一 or 22 廿二), they are written vertically. This is, at times, also the case for numbers made up of three characters (i.e. 51 五十一). In most cases, however, numbers consisting of more than two characters are written in two vertical columns reading from left to right. In a sense, the orientation only changes when there is not enough space for the numbers to fit in a single column. A characteristic feature of the foliation in the manuscript is that when the second column contains only one character, it is placed in the middle, rather than at the top of that column, which would be the usual way of beginning a new line. This way of filling up a block of rectangular space with several characters is reminiscent of the arrangement of Chinese characters in seals. Evidently, the individual who added the folio numbers on the side of the leaves thought of each number as a self-contained graphic unit, rather than text. 


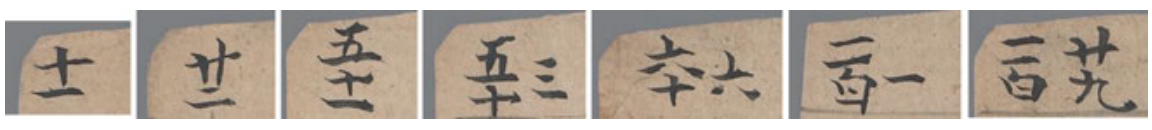

Fig. 36: Examples of folio numbers in manuscript P.3916. Starting from the left, the numbers are $11,22,51,53,66,101$ and $129 .(23.8 \times 8.8 \mathrm{~cm}$; Bibliothèque nationale de France)

Another example is Pelliot tibétain 102, a manuscript written entirely in Tibetan, except for the left-to-right Chinese folio numbers running at 90 degrees to the main text (Fig. 37). As it had once been a large volume, the folio numbers go up to 200. The number 199, for example, consists of five characters arranged in three separate columns reading from left to right. Matching the orientation of the Tibetan text, the folio numbers could have been comfortably written in a single vertical line on the margin. Instead, the writer chose to write them in this manner, demonstrating that he considered the numbers to form discrete units or blocks, rather than ordinary text.
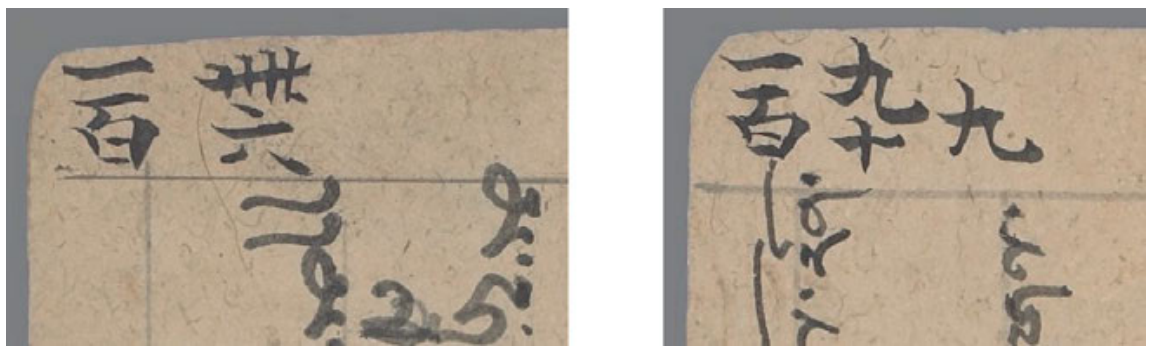

Fig. 37: Folio numbers in manuscript Pelliot tibétain 102, rotated 90 degrees to the Tibetan text. The numbers are 146 and $199 .(23.7 \times 8.7 \mathrm{~cm}$; Bibliothèque nationale de France $)$

Examples of continuous Chinese text reading horizontally from left to right are more conspicuous. One such manuscript is P.3922 with the Faju jing 法句經 (Skt. Dharmapada; Verses on the Dharma) and another text identified as the Dunwu zhenzong yaojue 頓悟眞宗要决 (Essential Teachings According to the True Principle of Sudden Awakening). The surviving portion of the manuscript consists of nine pothi leaves $7-7.3 \times 28.5-29.8 \mathrm{~cm}$ in size, with Chinese characters running horizontally in a left-to-right direction (Fig. 38). The latter text is linked with early Chan Buddhism and is also known from scroll P.2799, the beginning of which preserves the full title as Dunwu zhenzong jingang bore xiuxing da bi'an famen yaojue 頓悟眞宗金剛般若脩行達彼岸法門要决. It consists of questions and answers between the layman Houmochen Yan 侯莫陳琰 (660-714) and the dhyāna 
master Zhida 智達, who are two identities of the same person. ${ }^{336}$ A considerably longer Tibetan version survives in a concertina manuscript (Pelliot tibétain 116) with pages of roughly the same dimensions $(7 \times 29.5 \mathrm{~cm})$ as the pothi leaves in P.3922. ${ }^{337}$ This reveals that the Chinese and Tibetan manuscripts were likely used within the same, possibly bilingual, community. The horizontal alignment and the direction of the text is clearly an attempt to emulate the Tibetan model and may be connected with the particular circumstances of the manuscript's use. Significantly, the text amounts to more than 4,000 characters, which is of a different magnitude to the small groups of characters in the folio numbers. This is a substantial amount of continuous Chinese text written in a manner typical of Tibetan texts.

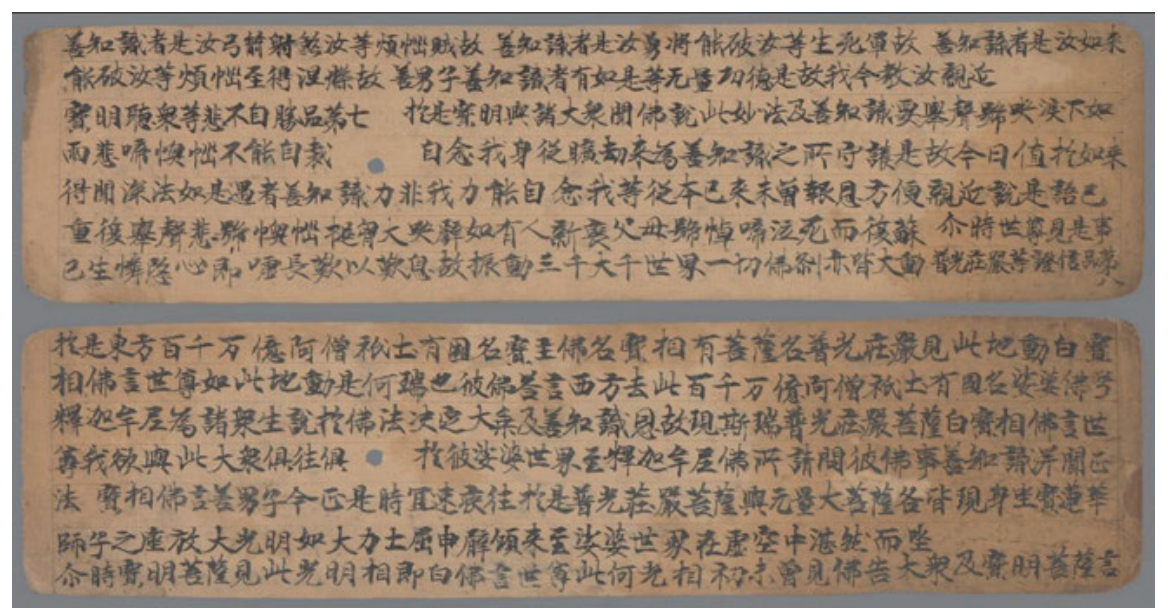

Fig. 38: Two pages from manuscript P.3922 with Chinese text written horizontally from left to right. $(7-7.3 \times 28.5-29.8 \mathrm{~cm}$; Bibliothèque nationale de France)

336 The two names refer to the same person, using his secular and monastic names. The Houmouchen 侯莫陳 surname is of Xianbei 鮮卑 origin and derives from the name of the Houmouchen tribes. This was an important aristocratic clan with a number of renowned military and civil officials before the eleventh century, when they gradually disappeared from the scene. This was due partly to them changing their original surname to Chen 陳 and other Chinese surnames. On the clan itself, see Chen Feifei 2018; on its connections with Buddhism, see Long Chengsong 2017.

337 On the Tibetan manuscript, see Ueyama 1976 and Tanaka and Robertson 1992, 57-78. Although this is a concertina, parts of the manuscript have been stitched together using thread. Cf. van Schaik 2014, 49-58. 
A similar example is P.3923, which contains the complete text of the Foding zunsheng tuoluoni jing 佛頂尊勝陀羅尼經 (Skt. Ușṇișavijayā-dhāraṇī; Dhāraṇī of the Buddha's Jubilant Corona), a popular scripture translated by Buddhapāla 佛 陀波利 (fl. 676). As with the previous example, this pothi also consists of nine leaves of very similar size $(6.9 \times 28.6 \mathrm{~cm})$, each with seven lines of text. However, in place of the brownish paper typical for the ninth century, the leaves of the manuscript have been dyed red, which is highly unusual. Fig. 39 shows two pages, the first of which contains the title and the name of the translator, all in horizontal lines reading from left to right.

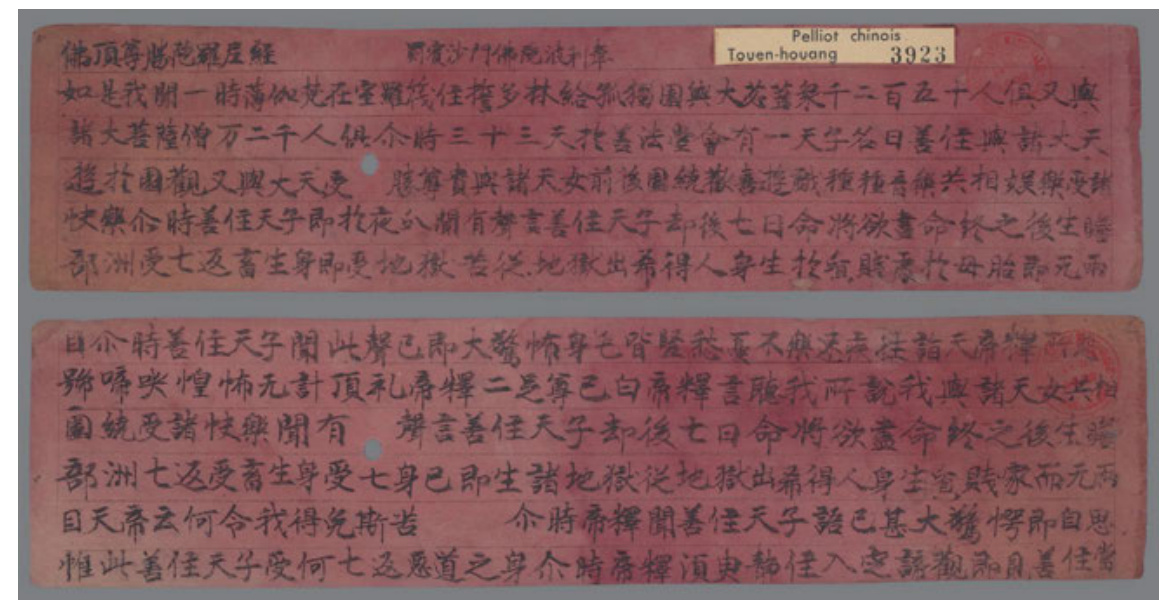

Fig. 39: Two pages from manuscript P.3923, dyed in red. $(6.9 \times 28.6 \mathrm{~cm}$; Bibliothèque nationale de France)

The two manuscripts are very similar in appearance, including the ruling, the string holes and the number of lines per page. The hand, however, is not the same. Needless to say, it is not possible to attribute the unorthodox direction of writing to convenience or other pragmatic considerations and we must acknowledge that the writers intended to replicate the visual arrangement of Tibetan manuscripts. This, in turn, would not have been a purely aesthetic preference but may relate to how these Chinese and Tibetan pothis were recited. It is possible that turning the leaves from bottom to top would have better suited the arrangement of ritual objects. Today we accustomed used to reading Chinese horizontally but, during the ninth century, these pothi leaves would have looked quite out of the ordinary. 
The pothi manuscripts with examples of horizontal Chinese characters reading from left to right are few in number and the practice of writing in this manner was by no means common. Nevertheless, taken together, the examples appear to be more than simply eccentric choices made by individual scribes. The pothi form in itself establishes a direct link to Tibetan manuscript culture. Chinese texts in this form basically follow the layout of Tibetan manuscripts, and the characters are written with a Tibetan-style hard pen. The Chan Buddhist orientation of the texts forms yet another obvious connection with Tibetan culture, more specifically with the over fifty Tibetan Chan manuscripts that found in the Dunhuang library cave. ${ }^{338}$ Unfortunately, not enough material has survived to determine the exact time frame of these manuscripts. Features associated with Tibetan manuscript culture signify that the manuscripts were probably produced during the Guiyijun period, as was the case for the vast majority of Tibetan pothis, excluding the group of sutras mass-produced for the Tibetan emperor. ${ }^{339}$

An example of horizontal writing not on a pothi leaf is manuscript P.3811, studied primarily for the Daoist talismans and seals it contains. ${ }^{340}$ The same manuscript also preserves several pages of incantations in horizontal lines of Chinese characters written from left to right (Fig. 40). The Chinese text appears to be a phonetic transcription of a non-Chinese language. In terms of its layout, it is written in double lines of nine characters, each of which concludes with the Tibetan end-of-clause marker shad, in the shape of a vertical line. Even without being able to reconstruct the source text, the horizontal lines and Tibetan punctuation marks confirm that the inspiration for writing Chinese characters this way must have derived from Tibetan scribal culture. ${ }^{341}$ The motivation of writing the text in difficult-to-read Chinese characters rather than the phonetic Tibetan alphabet is uncertain. It may have served individuals unfamiliar with Tibetan script

338 Regarding Chan Buddhist texts in Tibetan manuscripts from Dunhuang, see van Schaik and Dalton 2004, van Schaik 2014 and 2015. See also manuscript P.4646, a pothi manuscript that contains several Chan texts, including the apocryphal Chanmen jing 禪門經. For Chan texts in Tangut, see Solonin 2000; for those in Uighur, see Kudara 1992 and Zieme 2012.

339 An example of a long Chinese pothi is manuscript S. 5663 with a colophon dated to a yiwei 乙未 year. Because it refers to the monk Daozhen 道真 (d. ca. 987), active during the second third of the tenth century, the year must refer to 935, long after the end of the Tibetan period; see Teiser 1994, 144-145.

340 See, for example, Drège 1999a, 151-152, Wang Yucheng 2000, 38-39 and Huang 2017, 86. 341 While Drège 1999a, 152 tentatively ascribes this manuscript to the eighth century, Wang Ka 2004, 153-154 dates it to the Guiyijun period on the basis of the handwriting style. He also claims that the horizontal text is a Chinese transcription of Sanskrit sounds. Cf. Yu Xin 2006, 95. 
who nonetheless needed to be able to read the incantation aloud during a ritual. It was, however, more common to take advantage of the convenience offered by the Tibetan alphabet to record the sound of Chinese scriptures, which would certainly have been difficult to read for those lacking proficiency in Chinese. ${ }^{342}$

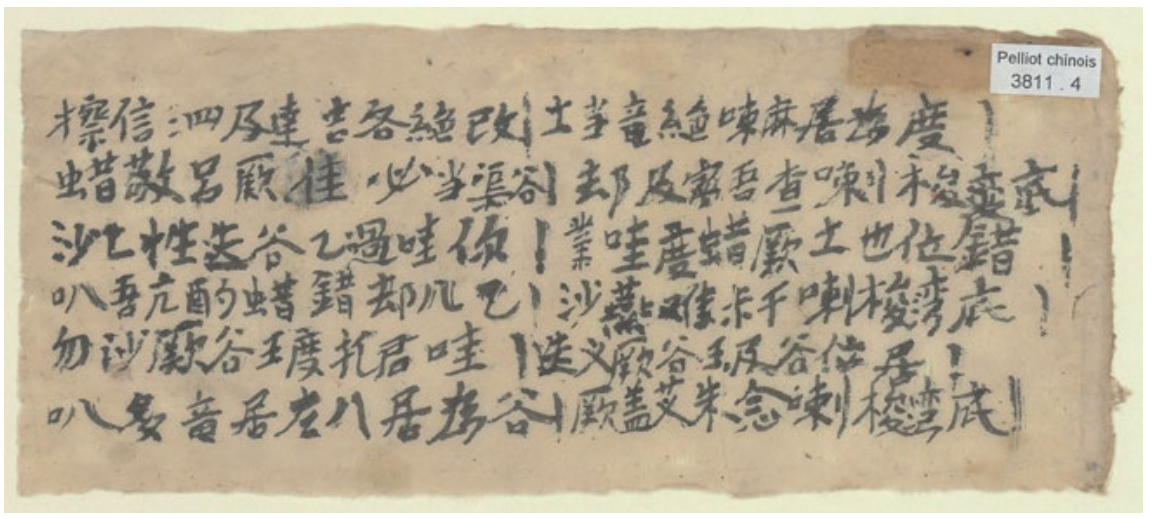

Fig. 40: Horizontal lines of Chinese characters on folio 4 of P.3811. (10-10.2 × $24.1 \mathrm{~cm}$; Bibliothèque nationale de France)

A fascinating manuscript is Pelliot tibétain 1257, a Sino-Tibetan glossary of Buddhist terminology, as it aligns side by side technical terminology in the two languages. ${ }^{343}$ This too is not a pothi but an unusual book form featuring ten sheets of paper attached to two bamboo sticks. As shown in Fig. 41, the Chinese text adapts to the left-to-right direction of the Tibetan text and reads either entirely horizontally or in short vertical columns from left to right. Thus the terms Jiufengshan 熟 峯山 ('Vulture Peak'), da gongdian 大宮殿 ('great palace') or Xumishan 須彌山 ('Mount Sumeru') all read horizontally, whereas Wangshecheng 王舍城 ('Rājagṛha'), youposa 憂婆塞 ('upāsaka; lay disciple') and a number of other terms read in vertical columns from left to right. Although some two-character terms appear as a single column, it is significant that no Chinese text reads from right to left, which would be the usual way of writing Chinese.

342 Takata 2000, 58-59.

343 On this manuscript, see Yamaguchi 1975, Apple and Apple 2017. 


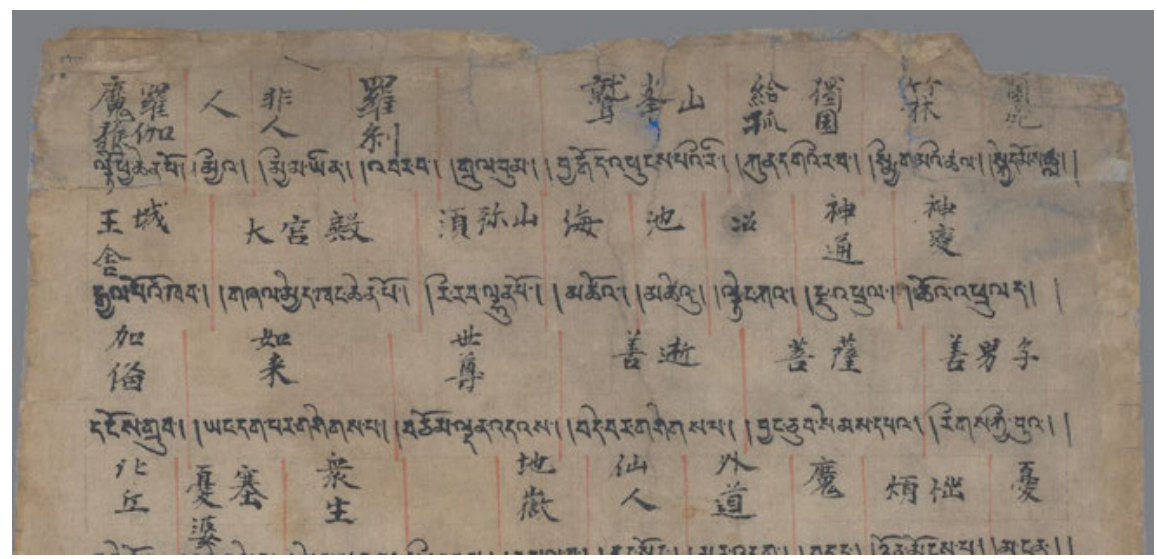

Fig. 41: Buddhist terminology in Chinese and Tibetan in manuscript Pelliot tibétain 1257. (29.5 $x 39 \mathrm{~cm}$; Bibliothèque nationale de France)

This example is noteworthy because it demonstrates that Chinese characters can change their direction under the influence of a different type of script. The fact that some Chinese terms read horizontally and others vertically (but still from left to right) shows that there was no well-established convention for the manner of writing them in such a context. Nevertheless, scribes felt compelled to maintain the left-to-right direction of the Tibetan text even when writing the Chinese equivalents of the terms. Just as noteworthy is how at times they wrote in vertical columns (from left to right), even though Tibetan is invariably written horizontally. Such vertical columns are in fact a mixed format that merges the vertical orientation of the Chinese script with the left-to-right direction of the Tibetan one. 


\subsection{Vertical columns written from left to right}

The other major type of left-to-right writing is vertical columns of Chinese text written from left to right. As mentioned earlier, it is possible to identify three subtypes based on where the examples occur. Thus, despite their typological similarity, the three subtypes do not reflect the same cultural influence.

\section{(i) Mandalas and amulets}

Manuscripts containing sporadic vertical columns of Chinese characters written from left to right include mandala-type designs and dhāranii-amulets combining image and text in complex geometrical compositions. ${ }^{344}$ These relate to esoteric Buddhist practices and, despite their vertical orientation, betray a strong Tibetan influence, as is clearly seen from the Tibetan counterparts of some of the compositions. These manuscripts originate in a highly specialised context and form a distinct group. At the onset, it must be emphasized that there are not many manuscripts containing such geometrical designs, and even fewer featuring left-to-right bits of text. There is only a small pool of cases, nonetheless the proportion of such cases within relevant manuscripts is significant.

Manuscript P.4519, for instance, contains a relatively large $(66.6 \times 60 \mathrm{~cm})$ square-shaped composition assembled from four smaller sheets of paper. All the text is written in the same hand; the text is in black ink and the images and structural lines are in red, while some of the shapes are filled with ochre colour. ${ }^{345}$ Straight red lines and images of deities divide the surface into smaller text areas containing the incantations. The boundaries seem to be driven entirely by visual design and do not coincide with textual divisions. It is in such delineated areas that some of the text reads in vertical columns from left to right. Fig. 42 displays the layout of the composition, showing the shape and format of text areas.

344 On this type of manuscripts, see Copp 2014 and Sørensen 2019; cf. Drège 1999a, 154-156.

345 For a useful description of P.4519, see Soymié et al. 1995, 157-160. 


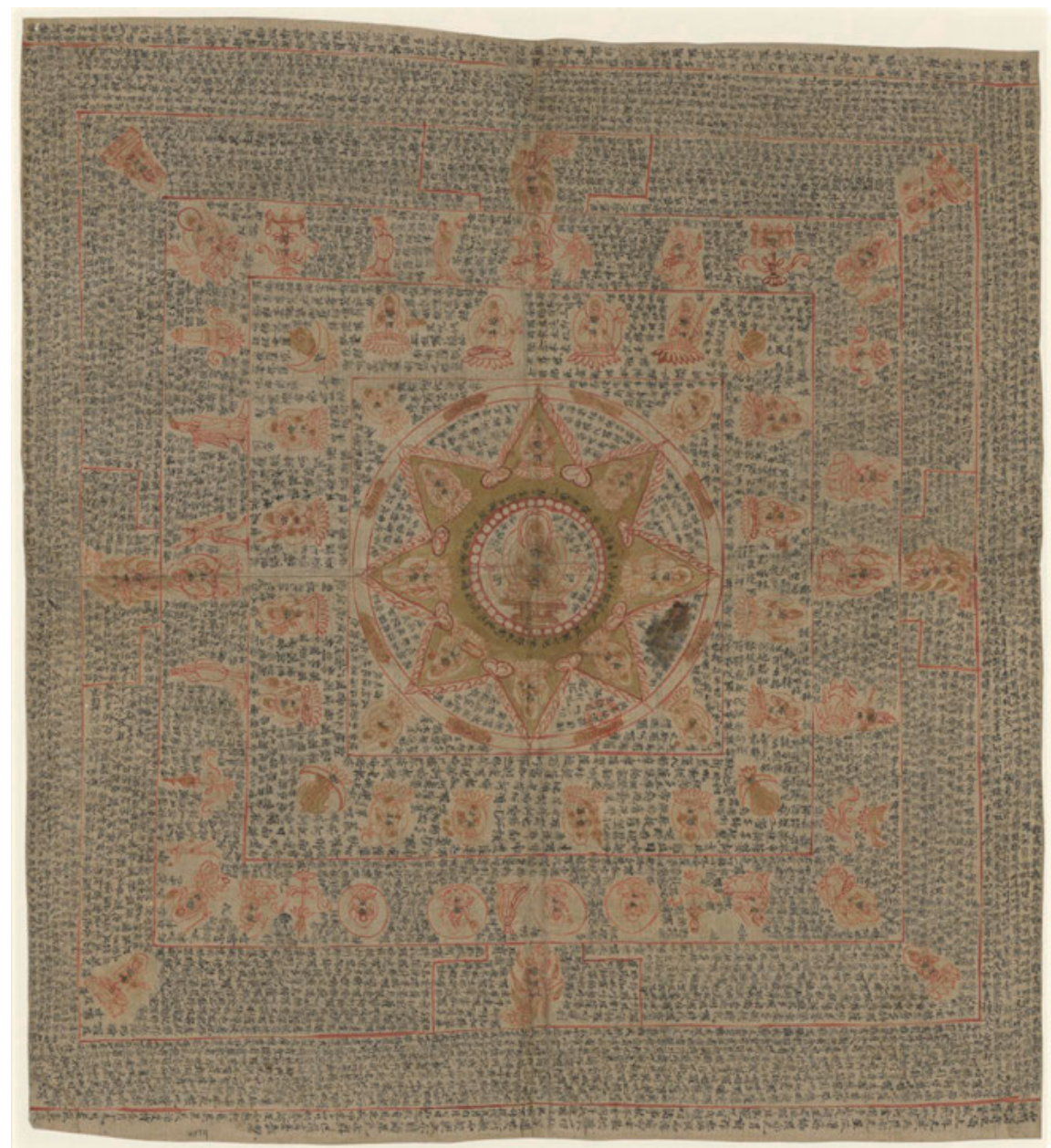

Fig. 42: The overall layout of manuscript P.4519, a dhāraṇī-amulet with a geometrical design. $(66.6 \times 60 \mathrm{~cm}$; Bibliothèque nationale de France)

The close-up detail in Fig. 43 illustrates the way sections of text appear inside the contoured areas. The text on the left side of the image begins with the words '... contemplate this, I shall explain it to you step by step' 思念之吾當為汝分別 演說. These words are from the Foshuo suiqiu ji de da zizai tuoluoni shenzhou jing 佛說隨求即得大自在陀羅尼神呪經 (The Scripture of the Dhāranī SpiritSpell of Great Sovereignty, Preached by the Buddha, Whereby One Immediately Attains What Is Sought; T1154, 20), a text translated by the Kashmiri monk 
Manicintana (Baosiwei 寶思惟, d. 721). ${ }^{346}$ The quote begins in mid-sentence at the lower left corner of the text area on the left, continuing from the text area above it, which ends with the words 'You [should contemplate this] earnestly...' 汝善 (in the bottom right corner of that area). As the image shows, the Chinese characters in the individual text areas read in vertical columns from left to right.

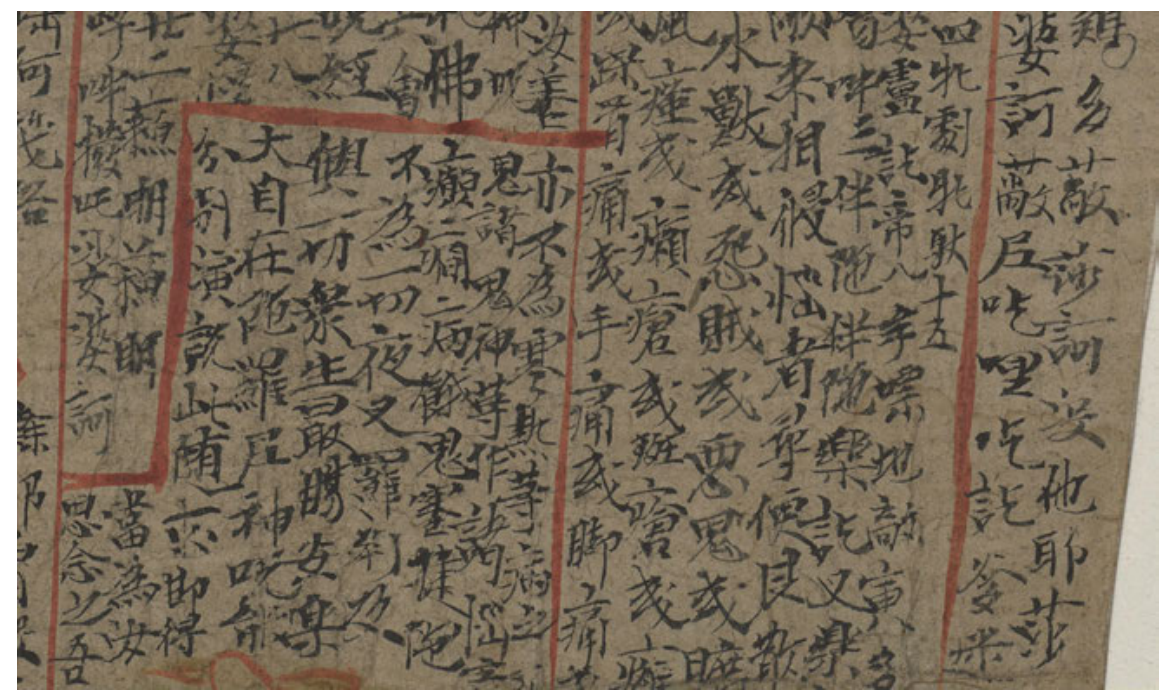

Fig. 43: Delineated text areas with text reading in vertical columns from left to right; detail from P.4519.

The visual arrangement of the amulet itself does not justify this direction of writing and part of the text indeed reads in the 'normal' direction. In other similar manuscripts (e.g. P.3982, P.4912), the text is written entirely in the usual manner, making P.4519 an exception, rather than the norm. The manuscript has, however, apparent similarities with Tibetan dhāraṇi-amulets, such as Pelliot tibétain 389 (Fig. 44), which has an almost identical composition but the text is in Tibetan and does not fill the surface to the extent of the Chinese text in P.4519. ${ }^{347}$ It is therefore probable that the left-to-right direction of writing, despite its vertical alignment, relates to Tibetan scribal culture and esoteric Buddhism. ${ }^{348}$

346 On Manicintana, see Forte 1984. The English translation of the scripture is from Copp 2014, 64. 347 On Pelliot tibétain 389, see Lalou 1936. Note also that this manuscript is about a quarter of the size of P.4519.

348 On esoteric drawings, see Luczanits 2009. 


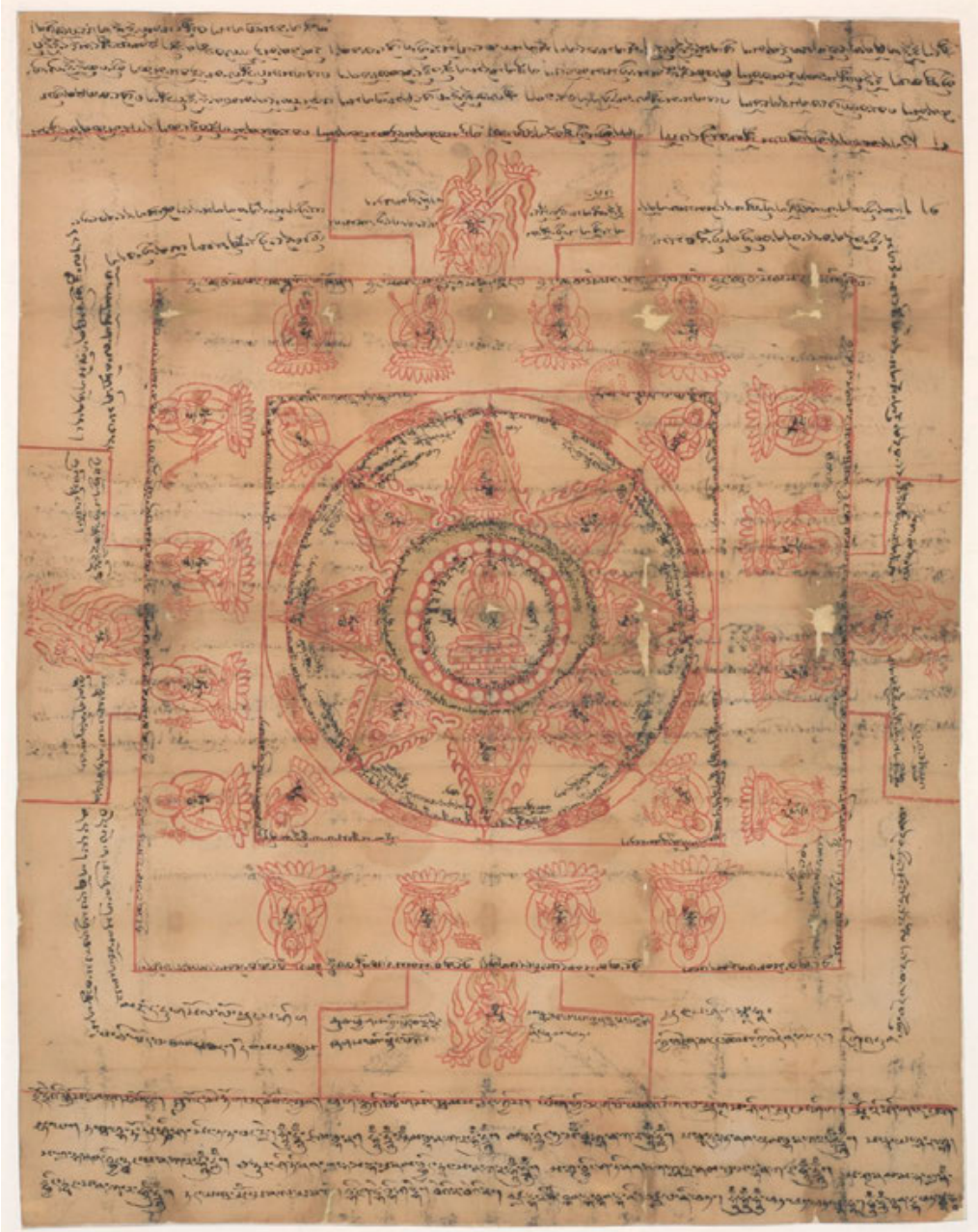

Fig. 44: A Tibetan dhāraṇi-amulet, Pelliot tibétain 389. $(31.7 \times 40.5 \mathrm{~cm}$; Bibliothèque nationale de France)

A different type of layout is seen in manuscript S.4690, which is a model of an amulet to be borne by monks. ${ }^{349}$ At the centre of the composition is an eightpetalled flower enclosing a double circle with the inscription 'for those worn by monks, paint a Diamond Spirit in the centre of the incantation' 僧帶者於咒心中

349 Copp 2014, 114-117. 
畫作一金剛神, which is a quote from the scripture translated by Manicintana. ${ }^{350}$ As Fig. 45 shows, this text reads from left to right. The same text appears in the same way in manuscript S.6264, a different copy of the amulet model, demonstrating that the atypical direction was not an ad hoc arrangement but an integral part of the composition. This second model features less text and may not have been as complete as $\mathrm{S.4690}$ but the inscription at the centre of the design is already present. The central location of the inscription excludes the possibility that the direction of writing was related to symmetry or balance.

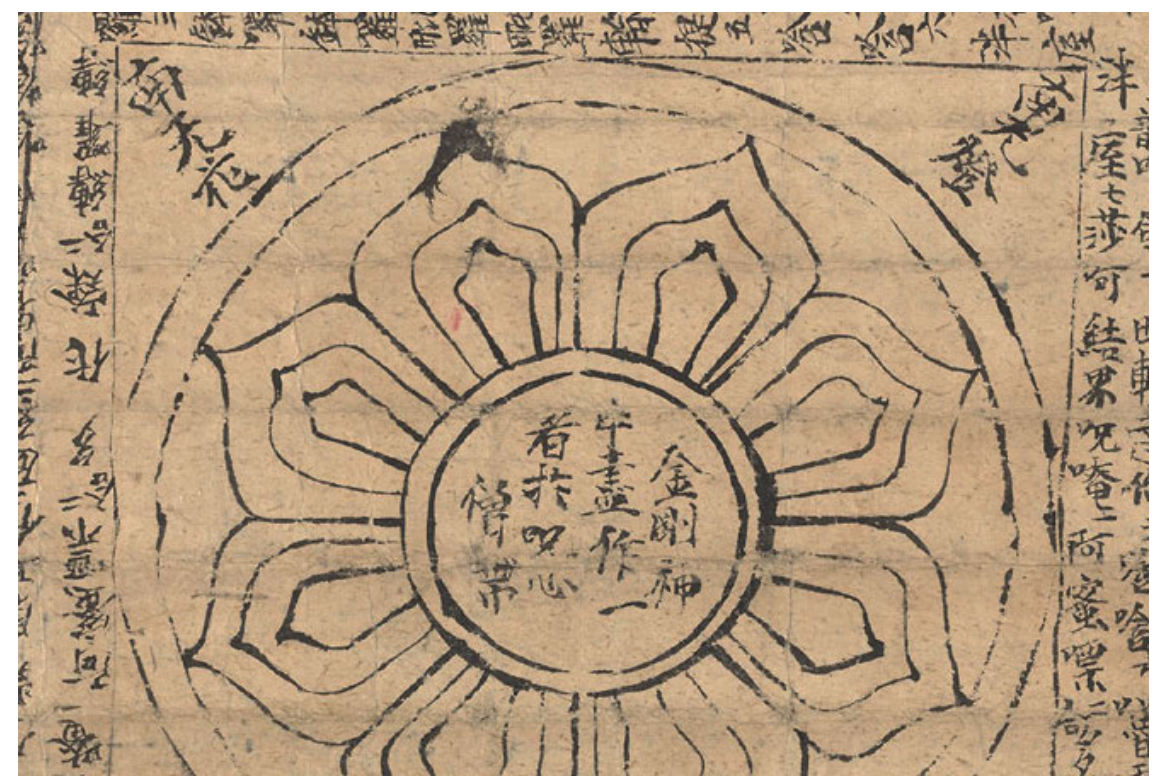

Fig. 45: Central part of the amulet model in manuscript S.4690. $(30.5 \times 39.9 \mathrm{~cm}$; The British Library)

Pelliot sanscrit Dunhuang 8 is an assembly of 12 smaller bits of printed leaves pasted together into a rectangular form. The central part of the composition is the Sheng Guanzizai pusa qianzhuan miezui tuoluoni 聖觀自在菩薩千轉滅罪陀羅

350 Copp (ibid., 115) notes that the character 畫 is written in these two manuscripts as 盡. The two characters are indeed sometimes written very similarly in the Dunhuang manuscripts and thus cannot always be distinguished purely based on their graphic form. The context and the link with the source text confirm that the character in question writes the word hua 畫 ('to paint, draw'). 
尼 (Thousand-Turning Dhāranī of the Noble Bodhisattva Avalokiteśvara for the Eradication of Sins), with the figure of seated Guanyin encircled by the Sanskrit dhāranī (Fig. 46). ${ }^{351}$ On the two sides and beneath this central composition are 11 identical strips of framed paper with a spell called Jiu channan tuoluoni 救産難 陀羅尼 (Dhāranī for Relieving from Childbirth Difficulties), which were probably meant to be worn on the body by women in labour. ${ }^{352}$ The Chinese name of the spell, to the left of the Sanskrit text, reads in two vertical columns from left to right (Fig. 47). It is significant that it is a woodblock-printed text produced in multiple copies, corroborating that the direction of writing was an intrinsic part of the design. ${ }^{353}$

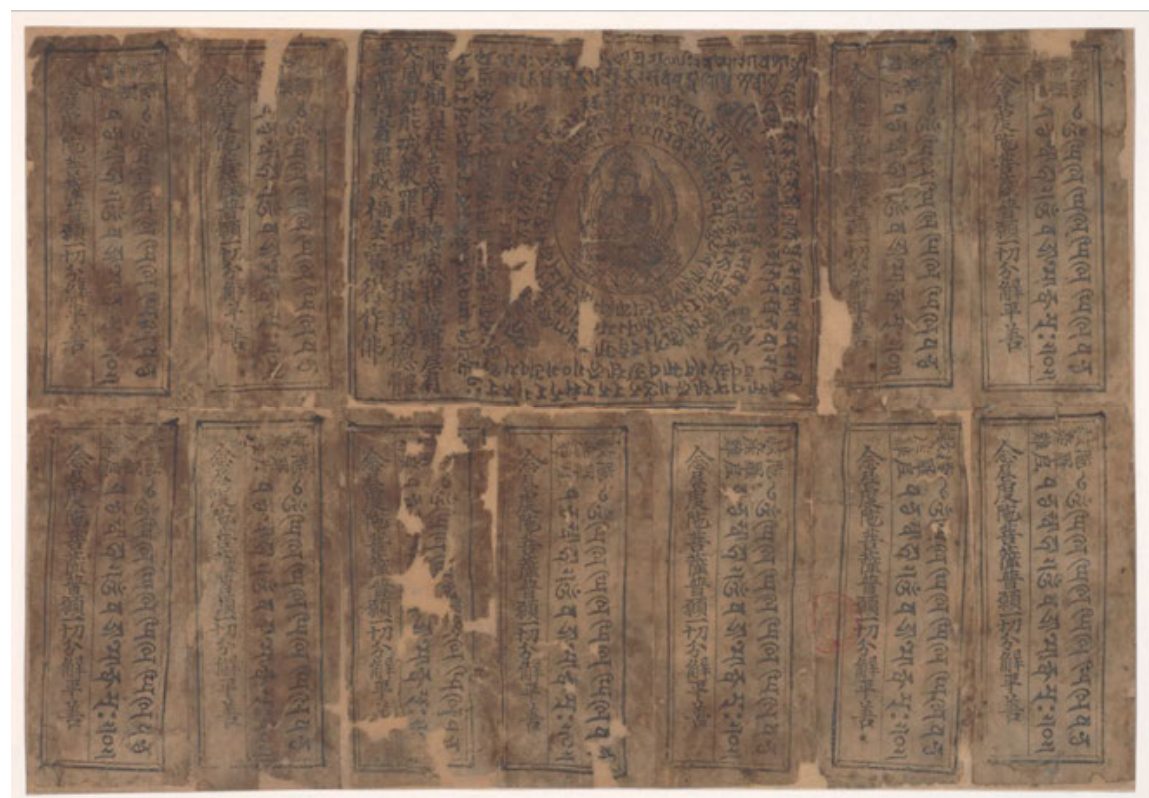

Fig. 46: Pelliot sanscrit Dunhuang $8 .(27.5 \times 40.2 \mathrm{~cm}$; Bibliothèque nationale de France)

351 The central composition also survives as stand-alone versions; see, for example, Hidas 2014, 105-109.

352 Copp 2014, 44-54, Li and Ma 2017, 340.

353 Similar collages constructed from multiple identical copies of the same image and text were not uncommon in Dunhuang; see Shen 2019, 80-86. 


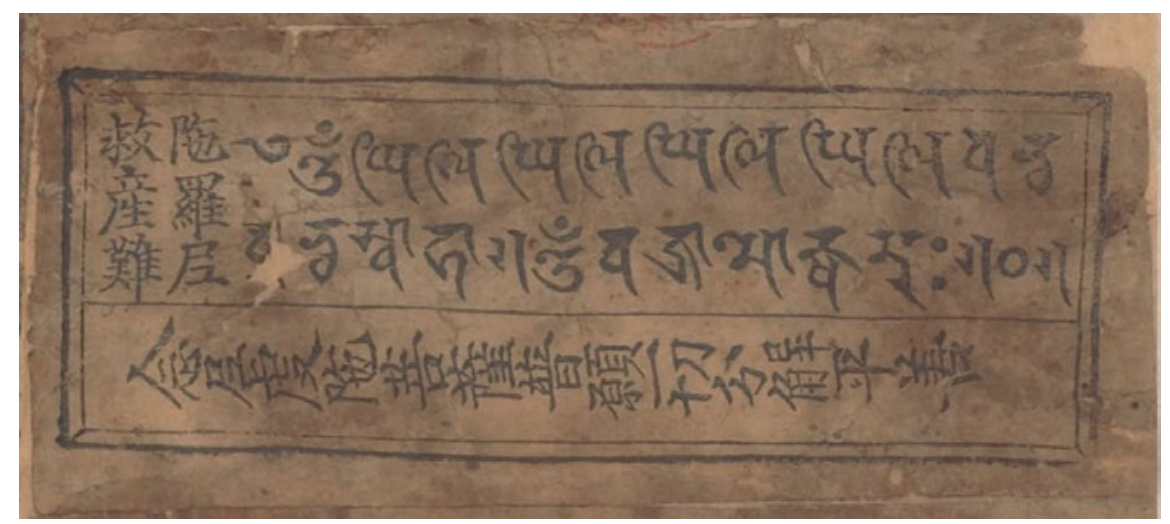

Fig. 47: Dhāraṇī for Relieving from Childbirth Difficulties, Pelliot sanscrit Dunhuang 8. $(13.7 \times 5.5 \mathrm{~cm})$

Occasionally, similar geometric designs feature text reading horizontally from left to right. An example is Stein painting 174 (Fig. 48), which contains a sketch of the ritual space for the recitation of the Ușṇișa vijaya dhāraṇī. ${ }^{354}$ As JeanPierre Drège points out, the setup conforms to the description that survives in a version of the scripture in the Tibetan canon. ${ }^{355}$ All of the text seems to be written in the same hand, although not enough characters are present for a conclusive verdict. Some but not all of the captions are written horizontally from left to right. Among these are the labels 'incense burner' 火爐, 'seat of spell master' 咒 師坐 and 'Heavenly King' 天王 (devarāja). Interestingly, of the labels for the gates in the four cardinal directions, the northern and western portals (beimen 北門 and ximen 西門) read from left to right but the southern and eastern portals (nanmen 南門 and dongmen 東門) read from right to left. Although graphic symmetry seems to play no role in the direction of writing, it is possible that the labels of the four portals reflect a conceptual juxtaposition. Strictly speaking, it is an example of horizontal writing, but in terms of its design and cultural background, it is clearly related to the examples on mandalas and amulets.

354 Waley 1931, 169, Fraser 2003, 154-156, Copp 2014, 100-101.

355 Whitfield and Sims-Williams 2004, 274. 


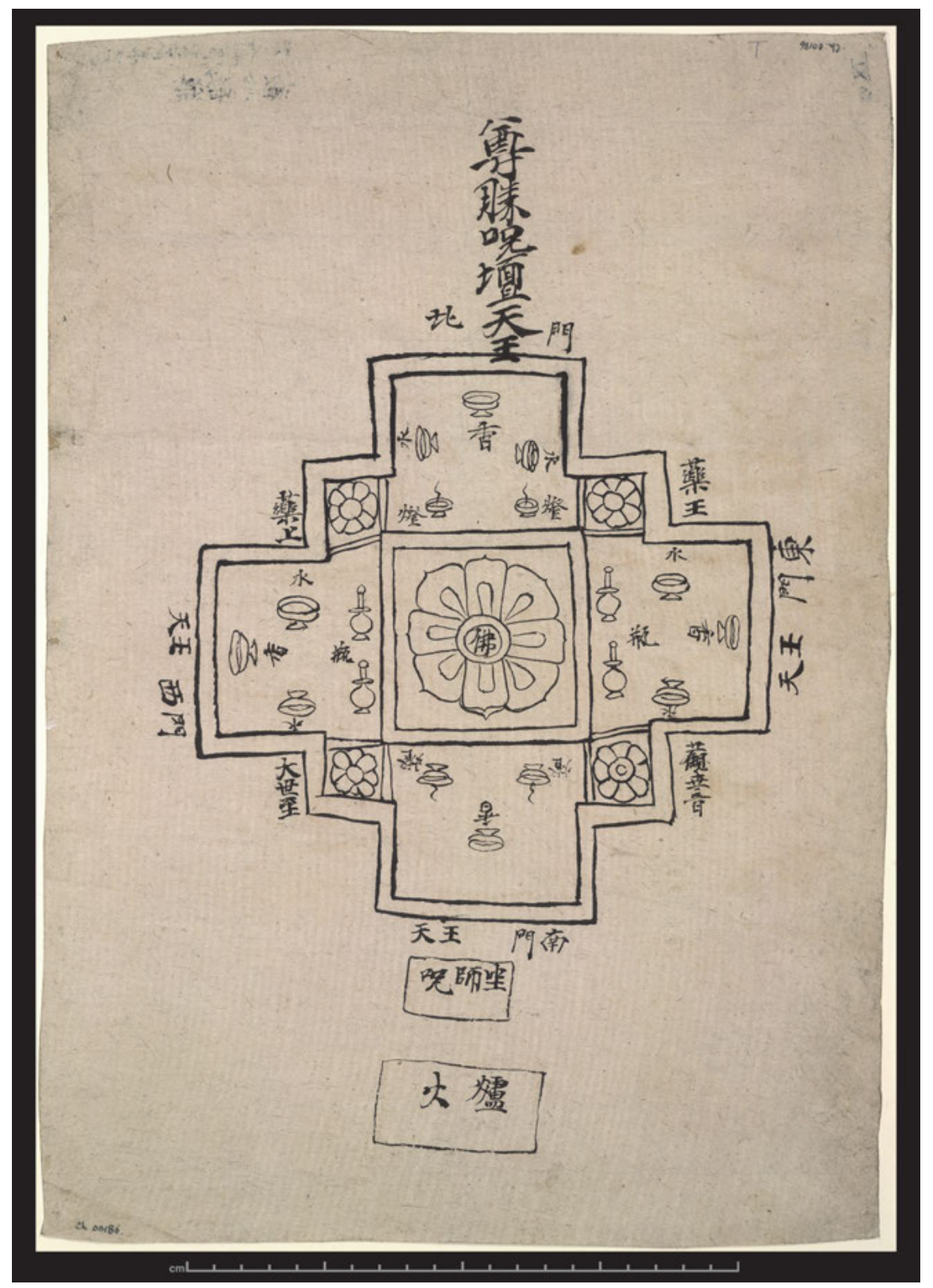

Fig. 48: Stein painting $174(44 \times 30.5 \mathrm{~cm}$; The British Museum) 
The above examples survive in mandala-type compositions with clear links to esoteric Buddhism. The esoteric Buddhist context and the unmistakable parallels with Tibetan manuscripts demonstrate the source of influence to be Tibetan scribal culture, even if in most cases the Chinese text remains vertical. None of the relevant examples are dated but a few specimens of printed amulets date from the last third of the tenth century. ${ }^{356}$ Naturally, these dates only give a general indication of the possible time frame of our manuscript examples but they point to the later part of the Guiyijun period.

\section{(ii) Margins and verso of scrolls}

Differing from the geometrical compositions in mandalas and amulets is a larger pool of examples of Chinese text written in vertical columns from left to right. They are not directly connected to esoteric Buddhism and typically occur on the margins or verso of scrolls associated with students and Buddhist donors. Occasionally, they appear on codices or other types of manuscripts, but are most common in scrolls. Table 6 contains a list of relevant manuscripts with an absolute date, expressed by means of a reign title and year. Whenever applicable, the penultimate column records the title of the main text on the recto. As association circulars are common in such manuscripts, the rightmost column indicates their presence, no matter how fragmentary.

Tab. 6: Instances of left-to-right writing in manuscripts with unambiguous dates.

\begin{tabular}{|c|c|c|c|c|c|}
\hline & Pressmark & $\begin{array}{l}\text { Dates in the manu- } \\
\text { script }\end{array}$ & $\begin{array}{l}\text { Relevant } \\
\text { date }\end{array}$ & Main text & $\begin{array}{l}\text { Cir- } \\
\text { cular }\end{array}$ \\
\hline 1 & P.2716 & $\begin{array}{l}855,864, \text { hai } \\
(855 / 867 / 879 / 892)\end{array}$ & $\begin{array}{l}867 / 879 / \\
892\end{array}$ & $\begin{array}{l}\text { Lunyu } \\
\text { [student colophon] }\end{array}$ & + \\
\hline 2 & P.2937 & 884 & 884 & Taigong jiajiao & - \\
\hline 3 & P.3666 & $867,888,890$ & 888 & Yanzi fu & + \\
\hline 4 & P.2738 & 869 & 869 & Taigong jiajiao & + \\
\hline 5 & P.2598 & 883 & 883 & $\begin{array}{l}\text { Xinji wenci jiujing chao } \\
\text { 新集文詞九經鈔 }\end{array}$ & + \\
\hline 6 & P.2825 & $\begin{array}{l}850, \text { xinhai (891), } \\
893\end{array}$ & $891-896$ & $\begin{array}{l}\text { Taigong jiajiao } \\
\text { [student colophon] }\end{array}$ & + \\
\hline
\end{tabular}

356 Drège 1999b. 


\begin{tabular}{|c|c|c|c|c|c|}
\hline & Pressmark & $\begin{array}{l}\text { Dates in the manu- } \\
\text { script }\end{array}$ & $\begin{array}{l}\text { Relevant } \\
\text { date }\end{array}$ & Main text & $\begin{array}{l}\text { Cir- } \\
\text { cular }\end{array}$ \\
\hline 7 & $\begin{array}{l}\text { S.329 } \\
+S .361\end{array}$ & $\begin{array}{l}857,892, \text { renzi } \\
\text { (892), 893, guichou } \\
(893), 894, \text { jiayin } \\
(894), 875,895\end{array}$ & 894,895 & $\begin{array}{l}\text { Shuyi jing } \\
\text { 書儀鏡 }\end{array}$ & + \\
\hline 10 & S.1386 & $942,943,944$ & & $\begin{array}{l}\text { Xiaojing } \\
\text { [student colophon] }\end{array}$ & + \\
\hline 11 & S.395 & 943,946 & & $\begin{array}{l}\text { Kongzi Xiang Tuo [xiangwen } \\
\text { shu] }\end{array}$ & + \\
\hline 12 & S.1907 & 946,948 & & $\begin{array}{l}\text { Fumu enzhong jing } \\
\text { 父母恩重經 }\end{array}$ & - \\
\hline 13 & S.2894 & 972,973 & & Vinaya text with commentary & + \\
\hline
\end{tabular}

The date is one the most important details permitting modern scholars to contextualise a manuscript. It is the most direct means for linking it to our existing knowledge of the historical context. Dates appearing in manuscripts, however, are not always reliable indicators of the moment when a particular bit of text was written down. Manuscripts may contain multiple texts added at different times or may be composite objects assembled from fragments of older manuscripts, some with their own temporal layers. For this reason, particularly for manuscripts featuring multiple texts or a variety of textual fragments, it is crucial to evaluate the validity of the date for each bit of text. Accordingly, the fourth column in the table signifies the date relevant for the left-to-right bit of text, as far as it is possible to determine.

Manuscript S.329 of the British Library, a relatively long scroll $(290 \mathrm{~cm})$ with a collection of model letters called Shuyi jing 書儀鏡 (Mirror of Letter Models) on the recto, is a concrete example. ${ }^{357}$ Zhao Heping 趙和平 demonstrated that this item is the first half of S.361, another scroll $(198 \mathrm{~cm})$ that contains the continuation of the same text. ${ }^{358}$ The verso of S.329 features a series of disconnected texts ranging from random notes and dates to association circulars, some written from left to right. The white arrows in Fig. 49 show the direction and length of two circulars written in this manner; the first is fragmentary but the second is complete. Elsewhere on the recto another complete circular reads in the conventional direction.

357 On the Shuyi jing, see Rong 1998, 84 and Wu Liyu 2018.

358 Zhao Heping 1990, 65. 


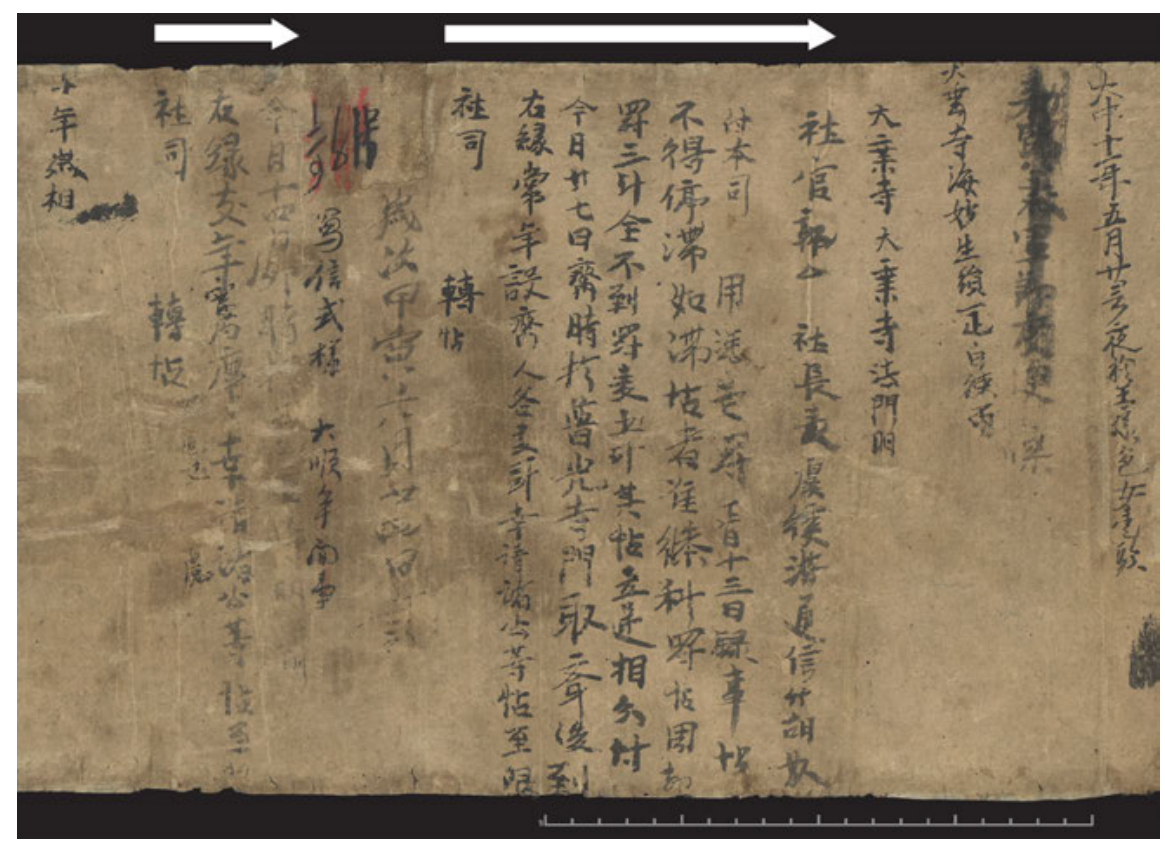

Fig. 49: Verso of manuscript S.329, showing a full and a partial left-to-right circular (marked with arrows). $(27.5 \times 290 \mathrm{~cm}$; The British Library)

The miscellaneous material on the verso is written in several hands, some faint to the point of being illegible. There are several dates on this side: the eleventh year of the Dazhong 大中 reign (857); a renzi 壬子 year, the third of Dashun 大順 (892); ${ }^{359}$ and the second of Jingfu 景福 (893). In addition, there is a jiayin 甲寅 year (894), as well as 'the second year of guichou' 癸丑二年, which must be 893 (i.e. the second year of Jingfu). Altogether, the verso contains five dates, and it seems that they, along with the other scribble-like bits of text, are random notes. This makes it difficult to determine whether they are relevant for the bits of text written from left to right. Incidentally, the date referring to the jiayin year (894) appears immediately after (i.e. to the right of) the circular fragment that reads from left to right and is written in the same hand and same kind of faded ink (Fig. 49). ${ }^{360}$

359 In reality, the Dashun reign only lasted two years and thus 892 was technically already the first year of the Jingfu reign.

360 The line in between the circular and the date, written in strong black ink (i.e. 'letterwriting models from the Dashun period’ 寫信式樣 , 大順年間事) is in the hand of Stein's secre- 
The verso of S.361, which used to be the other half of the original scroll, contains the following two dates: the second year of the Qianfu 乾符 reign (875) and the second of Qianning 乾寧 (895). The latter date appears twice and, as one of these occurrences is at the very end of the scroll, next to a longer fragment of a model letter written from left to right, it appears to be the most relevant date for that text.

Another example featuring multiple dates is manuscript P.2825, a scroll nearly $3 \mathrm{~m}$ in length, with a copy of the primer Taigong jiajiao. We have already discussed the colophon on the recto of this manuscript in Chapter Two, describing how the text was read aloud by the student Song Wenxian and written down by An Wende in the fourth year of the Dazhong reign (850). As in the previous example, the verso of the scroll has a series of seemingly random material, including miscellaneous notes and a lay association circular reading from left to right. There are three dates on the verso: the first year of the Dashun reign (891); the second of Jingfu (893) and the third of Qianning (896). Additionally, a reference to a xinhai 辛亥 year is present, most likely signifying 891. The dates all fall within the same five-year period but none of them can be confidently associated with the circular that reads from left to right. The date 896 is located in its immediate vicinity but the black ink is noticeably different from the faint ink of the circular (Fig. 50). ${ }^{361}$ Even so, it is relatively safe to assume that the circular dates not to 850, when the Taigong jiajiao on the recto was copied, but to around 891896 when the rest of the miscellaneous, scribble-like notes were added to the verso.

tary Chiang Ssu-Yeh. As usual, above his description are the Suzhou numerals in black and red ink.

361 The faintness of ink in part of the content in such scrolls is a common phenomenon, probably related to ink quality and how it ages. In fact, some of the text is so faded it is barely perceptible. The variations in intensity are evidently unrelated to the sequence in which the individual bits of text were written, as from a distance of a millennium the difference of a few years is insignificant. 


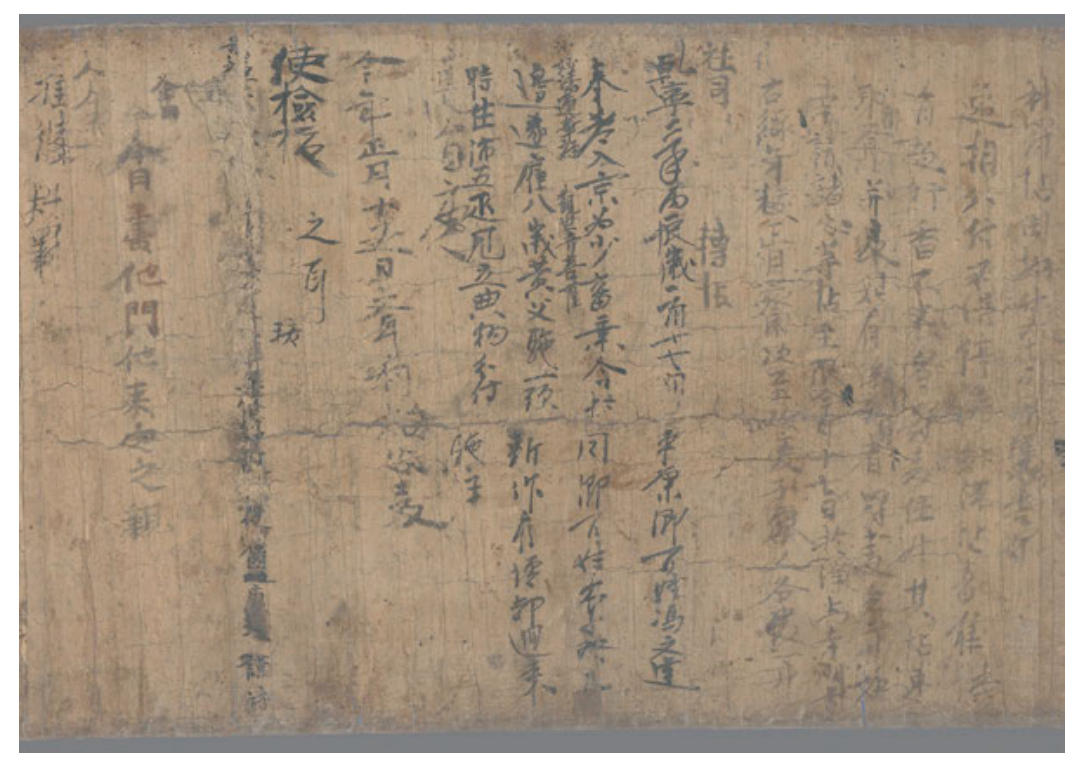

Fig. 50: Verso of manuscript P.2825, showing (on the right) a faint left-to-right copy of a circular and the date 896 (third year of Qianning), in stronger ink, to its left. $(29.5-30.7 \times 279.9 \mathrm{~cm}$; The British Library)

Yet another example is manuscript P.2716, the recto of which contains an incomplete copy of He Yan's commentary to the Lunyu. The writing style in the text and the colophon confirms that this is not a scholarly edition but a copy made by a student. Indeed, the colophon at the end of the text (Fig. 51) states that it was copied by the student Linghu Zaisheng 令狐再星 in the ninth year of the Dazhong reign (855). The two characters of the surname Linghu 令狐 in the colophon form a ligature (hewen 合文). Underneath this colophon, separated by a bit of space, are the words haiyuan ya 海源押, possibly meaning that the copying was approved by someone called Haiyuan. ${ }^{362}$ This could be the monastic name of a monk overseeing the student's work, although none of the other relevant manuscripts contain notes to this effect. To the left of the first colophon is another in a similarly incompetent hand, stating that this colophon was written by a boy (童子 tongzi) called Linghu Wenjin 令狐文進 in the fifth year of the Xiantong reign (864). Once again, the surname Linghu is written as a ligature.

362 Some scholars (e.g. Xu Jianping 2006, 367, Zhang Yongquan 2008, v. 4, 1728) read the second character without the 'water' radical as yuan 原 but, since this is part of a name, it is of no consequence for to the note's meaning. 


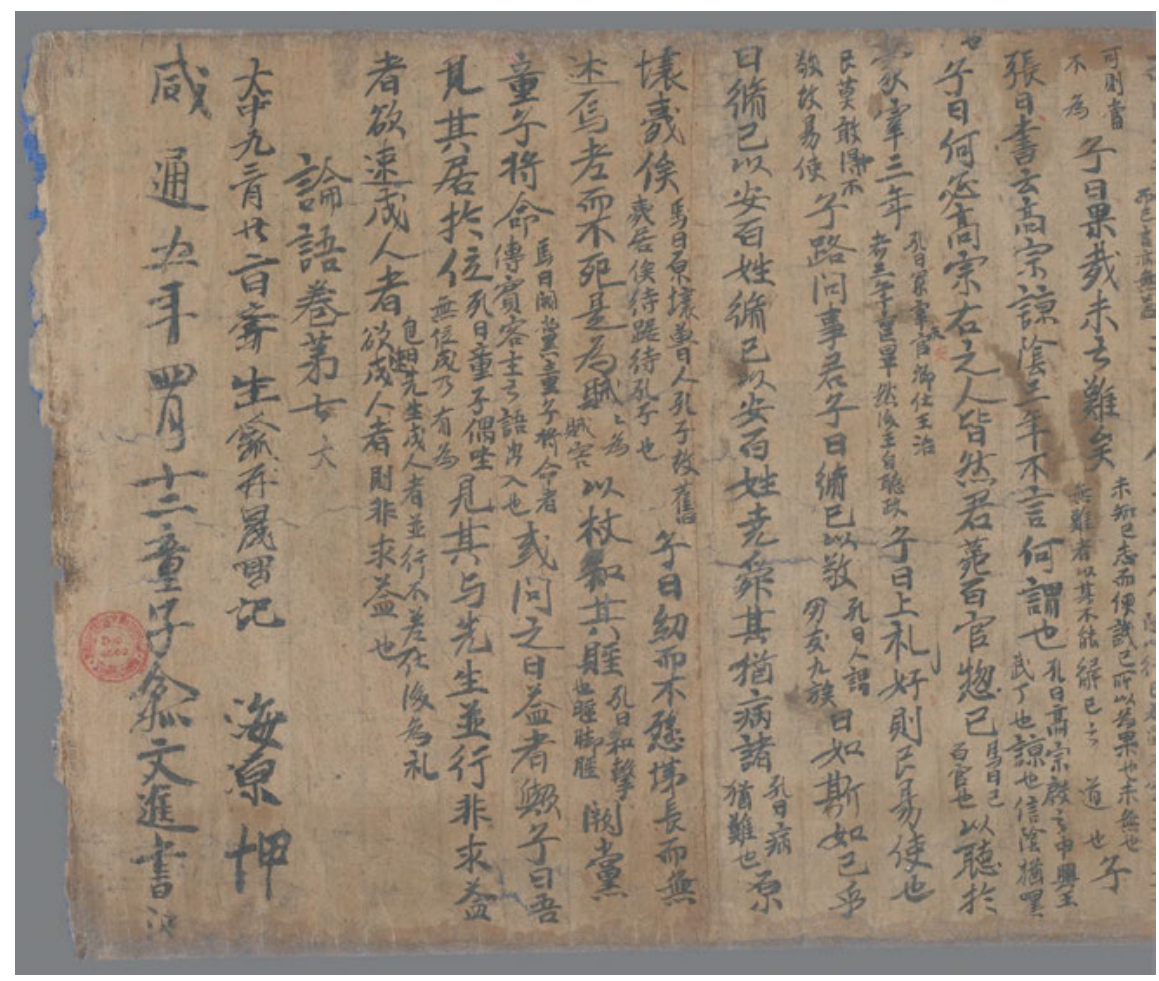

Fig. 51: The end of the recto of manuscript P.2716 with the two colophons. $(27.2-28.3 \times 158.4 \mathrm{~cm}$; The British Library)

Nine years separate the two colophons and while the first likely denotes the actual time of copying the Lunyu, the relevance of the second is not straightforward. It was apparently added at a later point in time by another member of the Linghu family but the exact relationship between the two of them is not clear. Wenjin may have simply used a manuscript copied by Zaisheng several years earlier. ${ }^{363}$ In any case, Wenjin could not have been Zaisheng's son because the nine-year gap between the two colophons implies a narrower age difference between them. Provided, of course, that they were roughly the same age when studying at the monastery, which is not necessarily the case. Nonetheless, Wenjin may have been a younger brother or another young male member of the larger family who inherited the scroll and became its second user.

363 This is a scenario suggested in Zheng Binglin 2001, 7. 
The recto of this scroll looks very similar to that of P.2825 and the dates of their colophons are also close in time ( 855 vs. 850). In addition, the verso of P.2716 likewise contains a copy of a circular written from left to right by an unskilled hand. To the right of it, another circular reads in the conventional direction. Far removed from these two circulars, at the rightmost edge of the verso is a reference to a hai 亥 year (i.e. Year of the Boar). As there is a hai year every twelve years, this date could theoretically refer to a number of actual years, including 855 seen in Linghu Zaisheng's colophon on the recto, or 867, which would be closer to the date in Linghu Wenjin's colophon (i.e. 864). ${ }^{364}$ As seen above in P.2825, the left-to-right bits of text on the verso are nearly half a century later than the colophon on the recto. Considering the parallels between the two manuscripts, the left-to-right text on the verso of P.2716 is probably also later than the dates of the colophons. The dates 867 , 879 or 892 are therefore more realistic.

Incidentally, the name Linghu Wenjin occurs in a long list of names at the end of a circular in another manuscript from Table 6, namely, P.2738. ${ }^{365}$ It comes as no surprise, therefore, that manuscript P.2738 is extremely similar to P.2716, featuring the Taigong jiajiao on the recto and a series of miscellaneous notes and scribbles on the verso. Among this material are two fragmentary copies of the Shang xiang Huang Qi tie 尚想黃綺帖 (I reverently think of Huang and Qi), ${ }^{366}$ a short piece of text attributed to the celebrated calligrapher Wang Xizhi 王羲之 (306-361). ${ }^{367}$ Clearly no effort has been made here to reproduce Wang Xizhi's calligraphy, the text is in a similarly careless hand as the rest of the scribbles on this side. Although one of the copies has been written in the usual direction, another one at the end of the verso reads from left to right. Due to damage to the end of P.2738, it is not possible to see the colophon on the recto, but the miscellaneous notes on the verso include two references to the tenth year of the Xiantong reign (869). This date, once again, is close in time to the dates in P.2716 and P.2825, supporting the initial impression that the two scrolls were created under similar circumstances.

$364 \mathrm{Xu}$ Jianping 2006, 367 proposes that the hai year refers to 855 seen on the recto.

365 Li Zhengyu 1987, 28.

366 Huang and Qi likely refer to the calligraphers Xia Huanggong 夏黃公 (Master Huang from Xia) and Qili Ji 綺里季 (Ji from Qili), two of the so-called Four Hoaryheads 四皓, who withdrew into the mountains from the tyrannical rule of the First Emperor of Qin 秦始皇 (r. 221-210 BCE); see Zhang Tiangong 2004. On the Four Hoaryheads, see Berkowitz 2000, 64-80 and Berkowitz 2014, 343-344.

367 On manuscripts with the Shang xiang Huang Qi tie excavated from sites at Khotan, Kucha, Turfan and Dunhuang, see Rong Xinjiang 2014; cf. Zhang Xinpeng 2018. The first few characters of the text, repeated over and over, also occur on the verso of a Tibetan manuscript, namely, Pelliot tibétain 4111. 
A pattern clearly emerging from the examples is that there is a significant overlap between manuscripts that contain left-to-right instances of writing and those written by students. Indeed, of the 13 manuscripts in Table 6, only the last item (S.2894) features a text that cannot be directly connected to an educational setting. The rest of the items contain secular texts commonly copied either by students studying at local monasteries (i.e. Lunyu, Taigong jiajiao, Yanzi fu, Kongzi Xiang Tuo xiangwen shu, Kaimeng yaoxun, Xiaojing) or those in other types of schools (i.e. Xinji wenci jiujing chao, Shuyi jing, Fumu enzhong jing). Three manuscripts feature student colophons expressly identifying them as having been copied and used by students associated with Dunhuang monasteries.

The above examples demonstrate that although some manuscripts include dates from the 850s onward, such early dates are probably not applicable to the left-to-right bits of texts on the verso. Often the content on the verso, including the text reading from left to right, postdates the main text copied on the recto by quite a few years. The earliest date we can confidently link with the practice of writing from left to right is 867. As for the upper end of this practice, the latest examples are from the early 970s. Although the sample base of unambiguously dated manuscripts here is limited, we should expect the same general time frame to be applicable for manuscripts with cyclical dates.

Table 7 lists manuscripts with cyclical dates expressed either in terms of the sixty-year or twelve-year cycle. Whereas within a person's lifetime such dates may have been perfectly adequate to record dates, from a distance of virtually a millennium they lose their specificity and become ambiguous. The fourth column records, whenever possible, the deduced date of the relevant piece of text. As earlier, the rightmost column indicates whether the manuscript includes fragments of association circulars, and the penultimate column records the title of the main text. 
Tab. 7: Instances of left-to-right writing in manuscripts with cyclical dates.

\begin{tabular}{|c|c|c|c|c|c|}
\hline & Pressmark & Dates in the manuscript & Deduced date & Main text & Circular \\
\hline 1 & S.6614 & $\begin{array}{l}\text { gengchen }(920 / 980), \\
\text { jiaxu }(914 / 974)\end{array}$ & & $\begin{array}{l}\text { Daban niepan jing } \\
\text { 大般涅槃經 }\end{array}$ & + \\
\hline 2 & P.2880 & gengchen $(920 / 980)$ & & misc. titles and excerpts & + \\
\hline 3 & $\mathrm{~S} .728$ & $\begin{array}{l}\text { bingshen }(876 / 936) \text {, } \\
\text { gengzi }(880 / 940)\end{array}$ & 936,940 & $\begin{array}{l}\text { Xiaojing } \\
\text { [student colophon] }\end{array}$ & + \\
\hline 4 & P.3698 & $\begin{array}{l}4^{\text {th }} \text { year, jihai }(879 / 939) \text {, } \\
\text { gengzi }(870 / 940)\end{array}$ & 939,940 & $\begin{array}{l}\text { Xiaojing } \\
\text { [student colophon] }\end{array}$ & + \\
\hline 5 & P.2439 & $\begin{array}{l}\text { jiyou (889/949), } \\
\text { jiashen }(864 / 924)\end{array}$ & & $\begin{array}{l}\text { Sapoduopini piposha } \\
\text { 薩婆多毘尼毘婆沙 }\end{array}$ & + \\
\hline 6 & P.3108 & $\begin{array}{l}\text { jiaxu }(914 / 974), \\
\text { gengchen }(920 / 980)\end{array}$ & & Qianziwen & - \\
\hline 7 & P.2690 & јіахи (914/974) & & $\begin{array}{l}\text { Nian'er wen } \\
\text { 廿二問, } \\
\text { i.e. Dasheng ershi'er wen ben } \\
\text { 大乘二十二問本 }\end{array}$ & - \\
\hline 8 & S.6461 & jiaxu (914/974) & & $\begin{array}{l}\text { Miaofa lianhua jing } \\
\text { 妙法蓮華經 }\end{array}$ & + \\
\hline 9 & S.5509 & jiashen (924/984) & & list of contributions & - \\
\hline 10 & P.3842 & $\begin{array}{l}\text { dinghai (867/927/ 987), } \\
\text { bingxu (866/ 926/986) }\end{array}$ & & confession text & - \\
\hline 11 & S.274 & wuzi (868/928/988) & & $\begin{array}{l}\text { Foshuo wuchang jing } \\
\text { 佛說無常經 }\end{array}$ & + \\
\hline 12 & P.3234 & $\begin{array}{l}\text { jiachen }(884 / 944) \text {, } \\
\text { renyin }(882 / 942) \text {, } \\
\text { guimao }(883 / 943)\end{array}$ & $944,942,943$ & $\begin{array}{l}\text { Commentary on the } D a \text { - } \\
\text { sheng baifa mingmenlun } \\
\text { kaizong yiji } \\
\text { 大乘百法明門論開宗義記 }\end{array}$ & - \\
\hline 13 & S.10564 & gengzi $(880 / 940 / 1000)$ & & - & + \\
\hline 14 & S.214 & $\begin{array}{l}\text { guiwei }(923 / 983), \text { jia- } \\
\text { shen }(924 / 984)\end{array}$ & 924 & $\begin{array}{l}\text { Yanzi fu } \\
\text { [student colophon] }\end{array}$ & + \\
\hline 15 & BD00268 & $\begin{array}{l}\text { guiwei }(923 / 983), \text { renjia } \\
(922 / 982)\end{array}$ & & Foshuo yan shouming jing & - \\
\hline 16 & BD01046 & $w u$ & & $\begin{array}{l}\text { Sifenlü shanbu suiji jiemo } \\
\text { 四分律刪補隨機羯磨 }\end{array}$ & - \\
\hline 17 & P.3692 & renwu (922) & 922 & $\begin{array}{l}\text { Li Ling yu Su Wu shu } \\
\text { 李陵與蘇武書 } \\
\text { [student colophon] }\end{array}$ & + \\
\hline 18 & S.1163 & gengxu $(890 / 950)$ & & $\begin{array}{l}\text { Taigong jiajiao } \\
\text { [student colophon] }\end{array}$ & + \\
\hline
\end{tabular}




\begin{tabular}{|c|c|c|c|c|c|}
\hline & Pressmark & Dates in the manuscript & Deduced date & Main text & Circular \\
\hline 19 & P.2680 & bingshen (936) & 936 & misc. Buddhist texts & + \\
\hline 20 & P.2537 & guiyou (913/973) & & $\begin{array}{l}\text { Lüechu yingjin } \\
\text { 略出籯金 }\end{array}$ & - \\
\hline 21 & S.5961 & guiyou (913/973) & & $\begin{array}{l}\text { Xinhe liuzi Qianziwen } \\
\text { 新合六字千字文 }\end{array}$ & \\
\hline 22 & P.3706 & $\begin{array}{l}\text { gengwu }(910 / 970) \text {, } \\
\text { guiyou }(913 / 973), \\
\text { wuyin }(918 / 978), \\
\text { bingwu }(886 / 946)\end{array}$ & $\begin{array}{l}970,973 \\
978,946(?)\end{array}$ & $\begin{array}{l}\text { Da foming chanhui wen } \\
\text { 大佛名懺悔文 }\end{array}$ & + \\
\hline 23 & P.3826 & $\begin{array}{l}\text { fifth interc. month of } \\
\text { wuzi }(868 / 928 / 988), \\
\text { dinghai }(867 / 927 / 987) \text {, } \\
\text { gengyin }(870 / 930 / 990)\end{array}$ & $988,987,990$ & $\begin{array}{l}\text { several Buddhist liturgical } \\
\text { texts }\end{array}$ & al \\
\hline 24 & P.4683A & yisi $(885 / 945)$ & & Daban niepan jing & - \\
\hline 25 & P.2717 & dingmao $(907 / 967)$ & & $\begin{array}{l}\text { Zhengshi zibao } \\
\text { 鄭氏字寶 }\end{array}$ & - \\
\hline 26 & $\begin{array}{l}\text { S.3011 } \\
(A+B)\end{array}$ & wuyin $(858 / 978)$ & & Lunyu & + \\
\hline
\end{tabular}

The first thing apparent about this table is that it has twice as many items as Table 6 above. This indicates that the people who produced these manuscripts preferred to use Tibetan-style cyclical dates. The titles of the main texts show that this group is quite different from the previous one. Less than half of the total items contain secular texts that can be linked to student lore. Even though five manuscripts feature student colophons, there is a high ratio of manuscripts with Buddhist texts.

Manuscript S.214 is a $144 \mathrm{~cm}$ scroll with a copy of the Yanzi fu (Rhapsody on the Swallow), executed in a mediocre hand. The colophon attributes the copying to Du Yousui 杜友遂, student at the Yong'an Monastery 永安寺 who copied this text at the end of the guiwei 癸未 year, which probably corresponds to $923 .{ }^{368}$ A second colophon, three-four months later (i.e. third month of the jiashen 甲申 year), names the same student. The verso of the scroll contains miscellaneous scribbles and several circulars, two of which are longer than one line

368 More precisely 924, as the date is at the very end of the lunar calendar; see Mair 1981, 239. Ikeda 1990, 466 agrees with this date. 
and thus have an identifiable direction of writing. ${ }^{369}$ As Fig. 52 shows, the one on the right reads in the conventional direction, while the faint one on the left runs in reverse. The white arrows above the image indicate the length and direction of the two circulars.

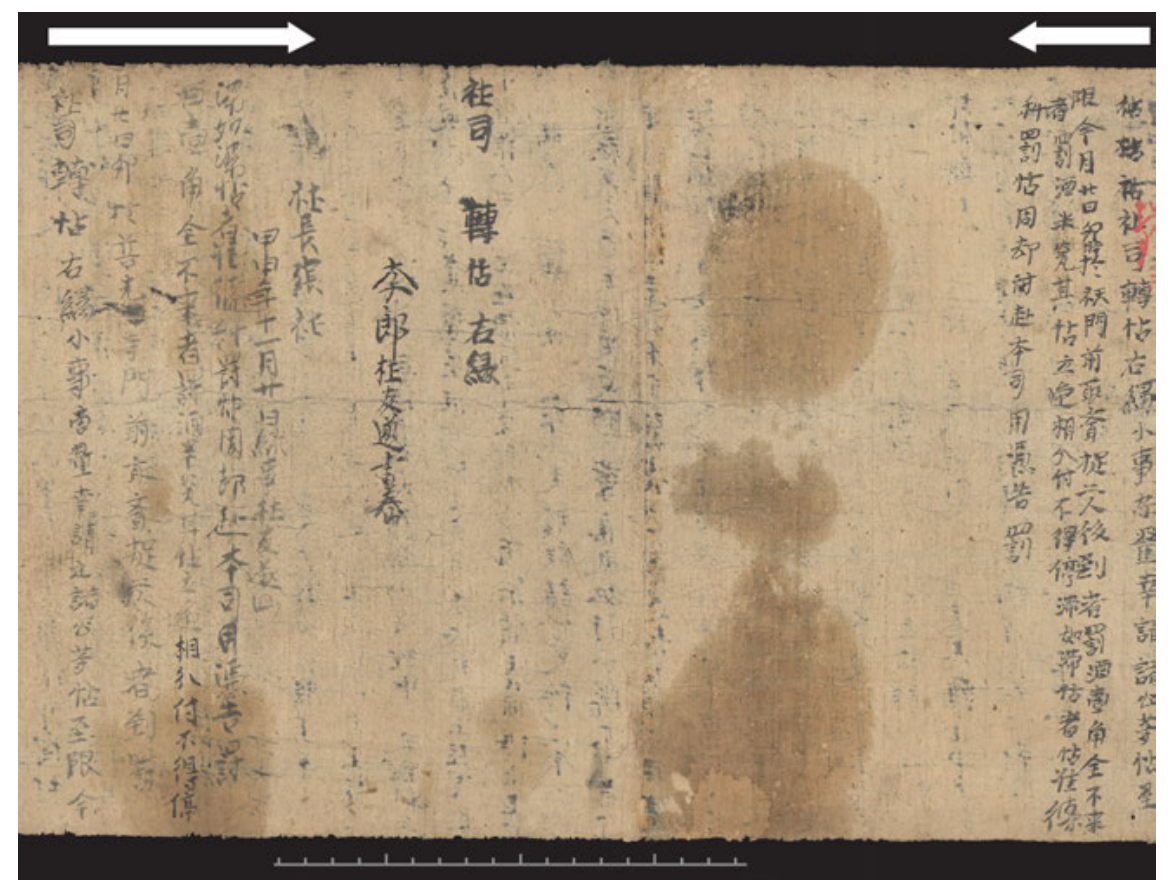

Fig. 52: The verso of manuscript S.214 with two circulars running in opposite direction. $(29.5 \times$ $144 \mathrm{~cm}$; The British Library)

The hand in the two circulars is very similar, possibly belonging to the same person. In addition, the opening formula of a circular with only six characters appears in the space between them, in larger characters and darker ink but still in a similar hand. As it is a single line of text, the direction of writing is uncertain. An indented line immediately to the left reads 'Scroll written by the student $\mathrm{Du}$

369 For a transcription of these two circulars, see Yamamoto, Dohi and Ishida 1989, 37. The two circulars are very similar in content, except that one of them requests members to meet in front of the Puguang monastery' 普光寺門前, whereas the other 'in front of the Zoroastrian [temple]' 祅門前; also, the latter is missing the date and signature from the end. 
Yousui' 斈郎杜友遂書卷. ${ }^{370} \mathrm{Du}$ Yousui's name also features in the faint left-to-right circular, which dates to the eleventh month of the jiashen year (924), eight months after the second colophon on the recto. The name, the date and similar handwriting establish a direct connection between the two sides of the scroll, suggesting they were written by the same student over the course of several months. ${ }^{371}$ Unfortunately, all of the dates are in a cyclical format and thus do not reveal the precise year of the left-to-right pieces of text. Nonetheless, it is clear from its content and appearance that the scroll belongs to the same group as the manuscripts in Table 6 above and is probably close to them in time. The date 924 suggested by former research fits this time frame well.

Manuscript P.3706 presents a different example. Its verso mentions the years gengwu 更午 (910/970), guiyou 癸西 (913/973), wuyin 戊寅 (918/978) and bingwu 丙 午 (886/946). It also features, among the scribble-like notes, the name of the Kaibao 開寶 reign (968-976), which overlaps with the cyclical dates gengwu (970) and guiyou (973). Although Kaibao could theoretically also represent the beginning of the name of the Kaibao Monastery 開寶寺, the correspondence with the cyclical signs indicates that here Kaibao does in fact signify the reign period. Accordingly, the cyclical dates listed above must refer to 970 (gengwu), 973 (guiyou) and 978 (wuyin). ${ }^{372}$

Another manuscript dated with cyclical signs is P.3826 with the Kongzi gong Xiang Tuo xiangwen shu 孔子共項託相問書 (Discussion of Confucius with Xiang Tuo). ${ }^{373}$ The verso of the scroll contains miscellaneous fragments, including a contract for the hire of labour and a left-to-right fragment of the main text from the recto. There are also a number of cyclical dates, such as gengyin 更寅 (870/930/990), dinghai 丁亥 (867/927/987), and wuzi 戊子 (868/928/988), which are quite close to each other, regardless of their actual date. Fortunately, the month of the wuzi year is identified as the intercalary fifth month (run wuyue 閏五月), and as among the possible choices 988 was the only wuzi year with an intercalary fifth

370 The character xue 斈 (學) is written here in a way that is closer to the surname $\mathrm{Li}$ 李. As already observed in Chapter Two regarding manuscript P.2808, the problem seems to have been a deliberate attempt to use the non-standard form 斈, which may have been less familiar to the student.

371 Another case of left-to-right text on this side of the scroll is one of two copies of a heptasyllabic quatrain, which run symmetrically outwards from a central axis. The poem has no title and is not attested in other sources. For an annotated transcription, see Zhang Xihou 2006, v. 9, 4014-4016. Curiously, this part of the verso also contains a reference to Wang Xizhi's Shang xiang Huang Qi tie, discussed above in connection with manuscript P.2738 (dated 869).

372 The bingwu year remains an outlier but it could refer to 946.

373 The title is slightly different from the Kongzi Xiang Tuo xiangwen shu 孔子項託相問書 seen in other manuscripts but it is, of course, the same text. 
month, it is certain that the date refers to that year. ${ }^{374}$ Therefore, the gengyin and dinghai years signify 990 and 987.

There are also some completely undated manuscripts with examples of text reading from left to right. Sometimes they offer clues that help their dating, especially if they contain names or events known from dated documents. Table 8 lists instances of left-to-right writing in manuscripts with no date.

Tab. 8: Instances of left-to-right writing on undated manuscripts.

\begin{tabular}{|c|c|c|c|c|c|}
\hline & Pressmark & $\begin{array}{l}\text { Dates in the } \\
\text { manuscript }\end{array}$ & Deduced date & Main text & Circular \\
\hline 1 & P.3094 & - & & $\begin{array}{l}\text { Dasheng baifa mingmenlun kai- } \\
\text { zong yiji }\end{array}$ & + \\
\hline 2 & Дx-1377 & - & & - & - \\
\hline 3 & P.3319 & - & $\begin{array}{l}\text { second half of } \\
\text { ninth c. }\end{array}$ & $\begin{array}{l}\text { Da bore boluomiduo jing } \\
\text { 大般若波羅蜜多經 }\end{array}$ & + \\
\hline 4 & P.3136 & - & $\begin{array}{l}\text { after ca. } 880 \\
\text { (codex) }\end{array}$ & $\begin{array}{l}\text { Fomu jing, Foshuo bore boluomiduo } \\
\text { xin jing, Foshuo Molizhitian [pusa } \\
\text { tuoluoni] jing }\end{array}$ & - \\
\hline 5 & P.2473 & - & & $\begin{array}{l}\text { [Taishang] dongyuan shenzhou jing } \\
\text { [太上]洞淵神哠經 }\end{array}$ & - \\
\hline 6 & S.4747 & - & & $\begin{array}{l}\text { Xin pusa jing } \\
\text { 新菩薩經 }\end{array}$ & - \\
\hline 7 & $\mathrm{~S} .865$ & - & & Fumu enzhong jing & + \\
\hline 8 & S.2104(A) & - & & Dasheng baifa mingmenlun kaizong yiji & - \\
\hline 9 & S.4863 & - & & - & - \\
\hline 10 & $\mathrm{~S} .6104$ & - & & - & + \\
\hline 11 & P.3411 & - & after 914 & $\begin{array}{l}\text { Shi ende zan } \\
\text { 十恩德讚 }\end{array}$ & - \\
\hline 12 & P.4520 & - & & Bore boluomiduo xin jing & - \\
\hline 13 & P.5042 & - & & Bore boluomiduo xin jing & - \\
\hline 14 & P.3838 & - & $\begin{array}{l}\text { after ca. } 880 \\
\text { (codex) }\end{array}$ & astrological texts & + \\
\hline 15 & P.tib.1069 & - & & - & - \\
\hline
\end{tabular}

374 For dating manuscripts using intercalary months, see Zhang Xiuqing 2007, which shows that between the beginning of the Tibetan period (ca. 780) and the time of the sealing of the Dunhuang library cave (ca. 1006), 988 was the only year with an intercalary fifth month. 
None of the items in this table contains secular texts associated with educational practices. Most of the content is Buddhist but the table also includes a Daoist scripture. Several items have no main text. This is a major difference from the predominantly secular texts of lay students seen in Table 6 and, to a lesser degree, in Table 7.

Manuscript P.3319 featuring part of the Da bore boluomiduo jing 大般若波羅 蜜多經 (Skt. Mahāprajñāpāramitā-sūtra; Great Sutra on the Perfection of Wisdom) has several incomplete fragments of association circulars on the verso, as well as a student poem written poorly, in a left-to-right direction. No dates are present but at the beginning of the verso the note 'people of the Great Tang' 大 唐國人 appears in large bold characters and bright ink. Ning Ke 寧可 and Hao Chunwen 郝春文 speculate that the people of Dunhuang could have referred to themselves as 'people of the Great Tang' only during the period of Tibetan control or the early part of the Guiyijun period (certainly before the collapse of the Tang dynasty). Thus, they tentatively date the manuscript to the second half of the ninth century. ${ }^{375}$ Again, this does not conflict with the general time frame seen in Table 6.

The verso of manuscript P.3411 contains three lines, written from left to right, partially matching the title of military commissioners of the Cao family. This puts the date of the manuscript within the Cao dynasty's control of the Guiyijun period, that is, after 914. A more complete form of the same title, as well as the dates 938 and 939, appear in manuscript P.3931..$^{376}$

Two of the items in Table 8 are codices, which, as seen in Chapter One, appear in Dunhuang only towards the end of the ninth century. Of these, P.3136, a small booklet with a left-to-right colophon by a certain Li Shunzi who held the official title jiedu yaya, has already been discussed. The title connects the manuscript to the Guiyijun period, but the book form helps to narrow the time frame further to the period after around 880. The other codex in the table is P.3838, with two divination texts. On an empty stretch of space on folio 3 (left side) someone has added, in a left-to-right direction, the opening formula of a circular (Fig. 53). ${ }^{377}$ Although there are no dates within the manuscript, the codex form shows it cannot be earlier than the late ninth century. Nevertheless, the earliest attested date of a Chinese manuscript in a codex form corresponds to the time frame of writing from left to right pieces.

375 Ning and Hao 1997, 145; cf. Rong Xinjiang 1990.

376 This codex contains a variety of miscellaneous texts, including an account of a pilgrimage of an Indian monk to Wutaishan 五臺山; see Schneider 1987.

377 The folio number is that added by modern conservators. 


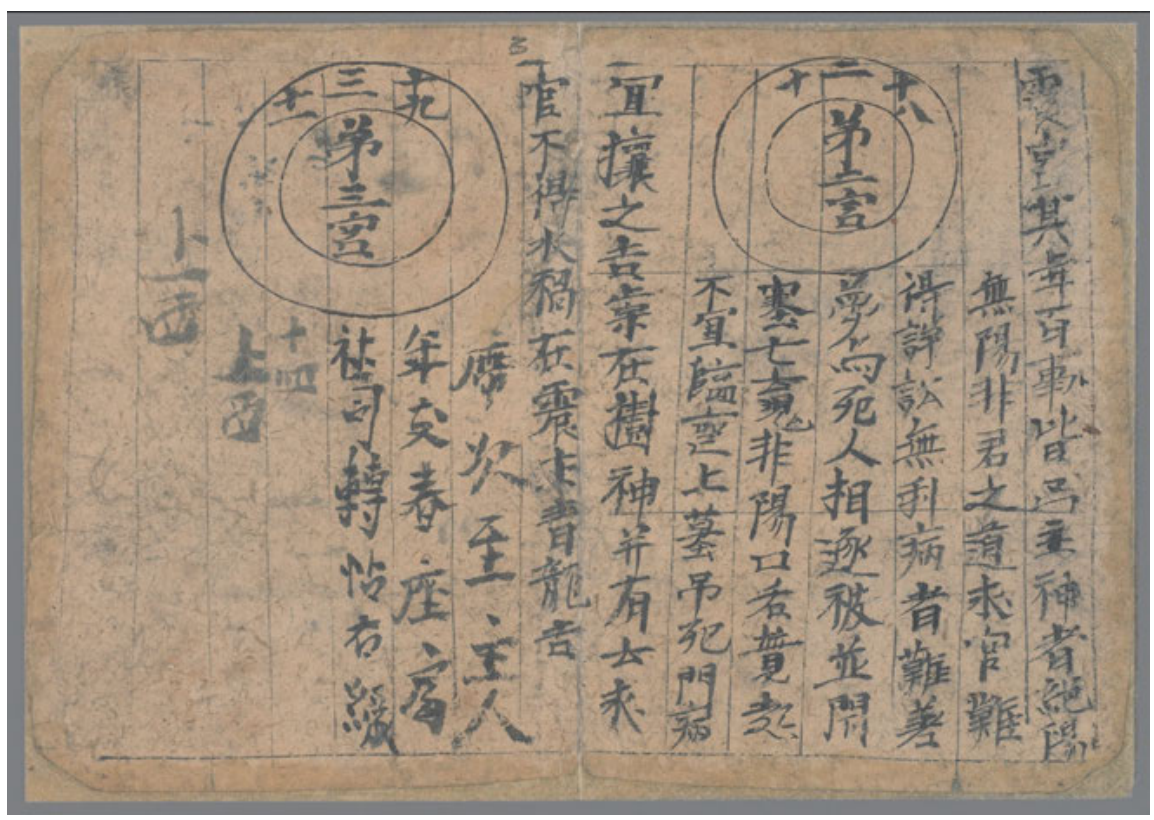

Fig. 53: Two pages from codex P.3838, with the opening formula of a circular in the lower half of the left page. $(14.5-14.8 \times 10,5 \mathrm{~cm}$; Bibliothèque nationale de France)

Looking through the manuscripts in Tables 6, 7 and 8, a pattern that emerges is that, in almost all cases, the examples of left-to-right bits of Chinese writing are smaller snippets of text, scribbles or notes on the verso or the margins of manuscripts. In the same manuscripts, most of the other material, especially the longer texts, reads in the usual direction. In other words, writing Chinese from left to right was not the normal or regular way of writing in manuscripts. Even those individuals who occasionally wrote short bits of text in this manner would, in most cases, have written in the traditional direction.

A conspicuous trait of such disconnected fragments is the frequent inclusion of association circulars, or circular fragments, sometimes merely a few characters in length. Indeed, quite often the fragments of circulars are the bits of text written from left to right. But even when this is not the case, they tend to co-occur in the same manuscript. Most manuscripts in Table 6 contain circulars. This pattern is unlikely to be a coincidence and points to a significant overlap between individuals who copied the circular fragments and those who wrote the left-to-right bits of text. Remarkably, the ratio of circulars is noticeably lower in manuscripts contain- 
ing cyclical dates or no dates at all (Tables 7 and 8). Clearly, bits of circulars were more common in manuscripts with unambiguous dates.

A similar pattern emerges when moving from Table 6 to Tables 7 and 8 in the decrease of secular texts copied by students. This, of course, also signals a change in the function of manuscripts, as the differences in dating practices likely relate to dissimilarities in the social context. The unambiguously dated manuscripts feature a disproportionally high ratio of primers and texts used as primers, including those followed by student colophons. As discussed in Chapter Two, the miscellaneous notes on the verso, including the left-to-right bits of text, were probably reminders of assignments students had to complete elsewhere. At the same time, the students who copied the main text may not have been those who wrote the notes on the verso, as later students may have continued using the same scroll for years or even decades.

The earliest date in a manuscript with left-to-right instances of text is 850 (P.2825) but, as argued above, this date does not pertain to the bit of text written in this way. The earliest actual date that can be linked with such examples is probably 867 (P.2716), although even this is only an indirect deduction. More conclusive is the date 891 (P.2825). As the latest attested date is 990 (P.3826, Table 2), the examples cover a period of about a century, falling firmly within the range of the Guiyijun period. This was, therefore, a scribal practice with clear geographical and temporal limits. Regrettably, there are only a few unambiguously dated manuscripts with such examples and thus the time frame of the practice may not be entirely accurate.

\section{(iii) Inscriptions on votive paintings}

In addition to the tens of thousands of Chinese, Tibetan and other manuscripts, the Dunhuang library cave also preserved hundreds of paintings on silk, canvas and paper. Many of the paintings contain votive inscriptions penned by the donors who paid for the objects. ${ }^{378}$ The murals inside the caves contain similar inscriptions, as well as cartouche inscriptions identifying Buddhist figures and narrative scenes. Donor inscriptions are of particular significance as many are unambiguously dated and include basic information about the donors. ${ }^{379}$ An apparent feature of the donor inscriptions from Dunhuang is how they mostly

378 The donor inscriptions of most Dunhuang paintings are collected in Ma De 1996. For the paintings in American collections, see Ma De 1999.

379 There is a wealth of recent research on votive paintings from the Guiyijun period, e.g. Soymié 1999, Li Yingjin 2010, Russell-Smith 2005, Sørensen 2020a and 2020b. 
read in vertical columns from left to right. The same is true of many framed captions naming the deities or labelling narrative scenes from scriptures.

I have identified 40 paintings with at least one left-to-right inscription. ${ }^{380}$ The items are presented in three tables below: Table 9 lists paintings with absolute dates that include a reign title; Table 10, those with cyclical dates; and Table 11, with no dates at all. Naturally, the lists include only inscriptions that are legible enough to establish the direction of writing. ${ }^{381}$ In some cases, the inscription is not visible (e.g. EO 1143, Stein 502), in others the writing is in a single column (e.g. MG 17665) or has no observable directionality.

Tab. 9: Dunhuang paintings with unambiguous dates.

\begin{tabular}{lllll}
\hline & Museum number & Central deity & Holding institution & Date \\
\hline 1 & Stein painting 28* & Guanyin & British Museum & 892 \\
2 & Stein painting 31 & Tejaprabha Buddha & British Museum & 897 \\
3 & Stein painting 14 & Guanyin & British Museum & 910 \\
4 & - & Bhaișajya-guru & Hakutsuru Museum & 929 \\
5 & Stein painting 41 & Maitreya & British Museum & 939 \\
6 & E0 1135 & Maitreya & Musée Guimet & 940 \\
7 & MG 17775 & Guanyin & Musée Guimet & 943 \\
8 & 1943.54 .1 & Maitreya's paradise & Arthur M. Sackler & 945 \\
& & & Museum & \\
9 & Stein painting 16 & Sākyamuni Buddha & British Museum & 953 \\
10 & MG 17695 & Guanyin & Musée Guimet & 955 \\
11 & Stein painting 216 & several bodhisattvas & British Museum & 956 \\
12 & Ax-68 & Guanyin & Hermitage State Mu- & 956 \\
& & & seum & \\
\hline
\end{tabular}

380 For the paintings, I use the published images from the main collections in Britain (Whitfield 1982-1985), France (Giès et al. 1994-1996), Russia (Menshikov et al. 1997-2005) and India (Chandra and Sharma 2012, as well as Waley 1931). Whenever possible, I rely on digital images available on the websites of the International Dunhuang Project (http://idp.bl.uk), the British Museum (http://http://www.britishmuseum.org) and the Bibliothèque nationale de France (http://gallica.bnf.fr). The inscription below the image of Bhaișajya-guru in the collection of the Hakutsuru Museum is visible in the colour plate in Bukkyō geijutsu 仏教芸術 (2019) 2, 1; Tabayashi 2019.

381 The museum number of Dunhuang paintings in the British Museum begin with 'Stein painting', followed by a number (e.g. Stein painting 54). In contrast, paintings in the National Museum of India, Delhi simply use the name ‘Stein' as the prefix (e.g. Stein 356). 


\begin{tabular}{|c|c|c|c|c|}
\hline & Museum number & Central deity & Holding institution & Date \\
\hline 13 & Stein painting 65 & Guanyin & British Museum & 957 \\
\hline 14 & MG 25486 & Guanyin & Musée Guimet & 959 \\
\hline 15 & - & Guanyin & Sichuan Museum & 961 \\
\hline 16 & Stein painting 19 & Kșitigarbha & British Museum & 963 \\
\hline 17 & Stein painting 24 & Guanyin & British Museum & 963 \\
\hline 18 & F1930.36 & Guanyin & Freer Gallery of Art & 968 \\
\hline 19 & Stein painting 52 & Guanyin & British Museum & 971 \\
\hline 20 & 27.570 & Guanyin & $\begin{array}{l}\text { Boston Museum of } \\
\text { Fine Arts }\end{array}$ & 975 \\
\hline 21 & MG 17659 & Guanyin & Musée Guimet & 981 \\
\hline 22 & Stein painting 54 & Guanyin & British Museum & 983 \\
\hline 23 & MG 17662 & Kșitigarbha & Musée Guimet & 983 \\
\hline 24 & 1943.57 .14 & Guanyin & $\begin{array}{l}\text { Arthur M. Sackler } \\
\text { Museum }\end{array}$ & 985 \\
\hline 25 & 11606 & $\begin{array}{l}\text { Bao fumu enzhong jingbian } \\
\text { 報父母恩重經變 }\end{array}$ & $\begin{array}{l}\text { Gansu Provincial } \\
\text { Museum }\end{array}$ & 991 \\
\hline
\end{tabular}

Other than the items in the table, I have been able to find only one unambiguously dated painting featuring only text written from right to left (i.e. in the conventional direction) and no text reading from left to right. This is Stein painting 5, dated to 864, earlier than all of the paintings in Table 9. Evidently, the practice of writing inscriptions from left to right had a temporal aspect and this painting predates the advent of this practice. It was not in vogue in 864 but by 892 was already gaining momentum. This matches the manuscript evidence, which dates the beginning of the practice to the 880s. From the entire list in Table 9, Stein painting $28^{\star}$ (dated 892) and Stein painting 14 (dated 910) are the only items which, in addition to containing a left-to-right inscription, also have text written in the 'normal' direction. ${ }^{382}$ All other items contain text written from left to right exclusively. This makes the paintings very different to the manuscripts, in which the number of items with left-to-right text is minimal in comparison with the overall quantity of manuscripts from the same period.

To demonstrate the arrangement of inscriptions and their directions, Stein painting $28^{\star}$ with the central figure of Guanyin (Fig. 54) presents a good example. The top left corner of the composition contains a partly damaged cartouche

382 In fact, in Stein painting $28^{\star}$, it is the central donor inscription that reads from left to right. 
with a yellow background bearing the words 'Wholeheartedly offered to the Compassionate [Bodhisattva] Guanshiyin, Saviour from Trouble’ 南無大慈悲救 苦觀世音[菩薩]一心供養. This inscription reads from left to right and thus fits our group. It is also noteworthy, that the text does not emanate from the central figure of the deity but runs towards it. The donors are depicted at the bottom of the composition, in a separate register. Of these, the main donors are the monk Zhigang 智剛 and the nun Shengming 勝明, whose names appear in green cartouches, in contrast to the yellow cartouches of the other donors. Both Zhigang and Shengming are identified as having the surname Sun 孫, indicating that they were of the same family. Of the two donors behind the monk, the first is the female Miaozhen 妙真, whose name could indicate a nun but her portrait clearly shows a lay devotee. ${ }^{383}$ The last person is called Hezi 和子 and seems to be a male devotee. ${ }^{384}$ As the inscriptions do not specify Miaozhen's and Hezi's surname, it is likely that they were also part of the same Sun family. The two nuns behind Shengming, called Pujing 普淨 and Minglü 明律, do not offer any clues to their identity. ${ }^{385}$ As their cartouches do not include the word gongyang ('to offer, worship'), they may have played a different role in the act of offering.

383 The name Miaozhen is evidently of Buddhist background and is also attested in Dunhuang as a monastic name; it appears, for example, in three lists of nuns in manuscript S.2614 (dated 895); in manuscript S.2669 (dated 865-870), the name appears in another list of nuns, which also gives her secular name as Song Weiwei 宋威威; see Dohi 2015, 1141-1142.

384 Dohi 2015, 363 lists (Sun) Hezi as a nun but I think Whitfield 1982-1985, v. 1, 323 is correct in that the picture shows a male lay devotee. Hezi is attested in the manuscripts with various surnames (e.g. Zhang, Wang, An) as a male given name.

385 Waley 1931, 47 misreads the names Pujing as Puzheng and Miaozhen as Miaochen; Whitfield and Sims-Williams 2004, 245 adopt the same readings. Waley also takes the character sun 孫 in the sense of 'grandson' and reads Sun Shengming 孫勝明 as 'the grandson Shengming', which does not work because both the main inscription and the portrait identify her as a nun. Nevertheless, reading sun as 'grandchild' is not altogether impossible and would make sense in this context. But, as in other inscriptions granddaughters are referred to using the word sunnü 孫女, the character sun 孫 in this place must signify the surname Sun 孫. 


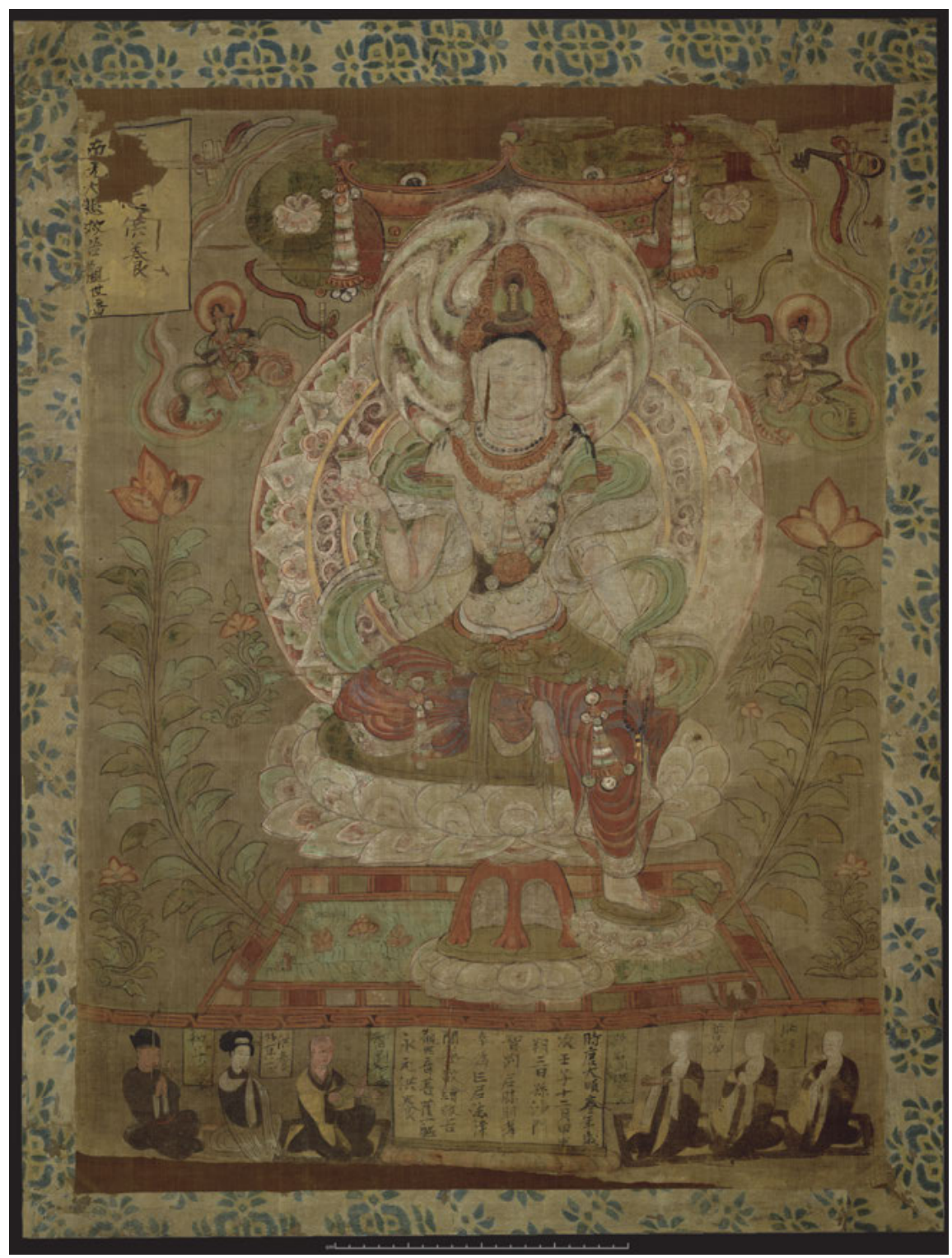

Fig. 54: Stein painting $28^{\star}$. $(83.3 \times 63.1 \mathrm{~cm}$; The British Museum $)$

The main donor inscription located at the centre of the bottom register states that the painting was commissioned by Zhigang, Shengming and others on behalf of deceased nuns and clerics. Naturally, the family ties between the do- 
nors raise the possibility that the painting may commemorate members of the same family. The inscription itself reads in the usual direction from right to left. But the two-line inscription with Miaozhen's name on the left is written in a leftto-right direction (Fig. 55). Thus, of the three multi-column inscriptions in this painting, two read from left to right, whereas the long central one reads from right to left. As mentioned above, this combining of directions in the painting may be due to its relatively early date, when the practice of writing devotional inscriptions from left to right was still gaining momentum.

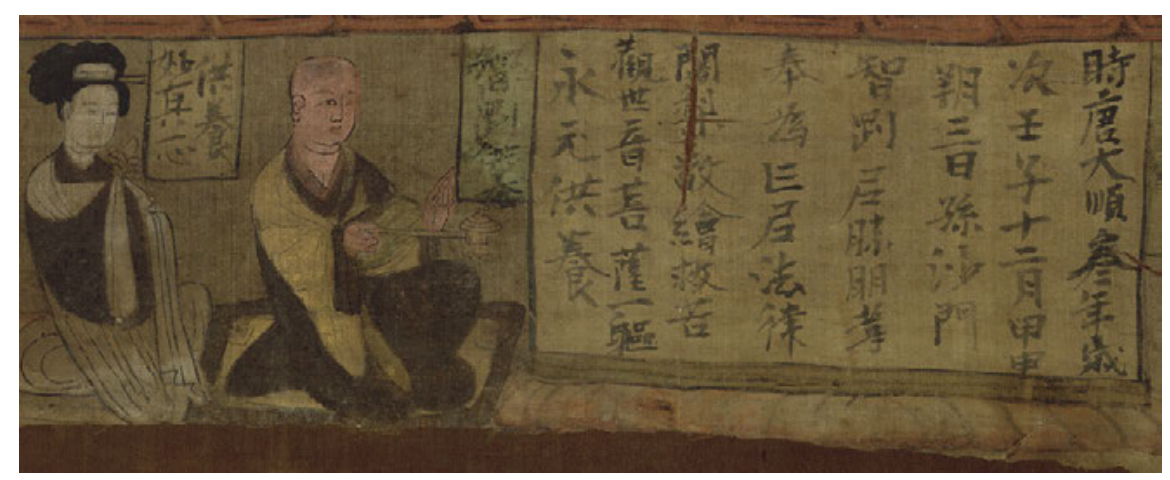

Fig. 55: A section of the bottom register in Stein painting $28^{*}$, with two inscriptions written in opposite directions.

While the paintings were obviously the work of trained professionals, the inscriptions in the cartouches were most likely filled in by the donors who commissioned the painting. This was the same type of personal participation in the devotional process already seen in the case of multiple-text manuscripts in Chapter One. This scenario is corroborated by the fact that the inscriptions sometimes, although certainly not always, appear in a decidedly untrained hand. There are also numerous empty cartouches among Dunhuang paintings, probably because donors had not yet appropriated them. ${ }^{386}$ In Stein painting $28^{\star}$, however, some of the inscriptions are in a very similar hand, suggesting that the same individual may have written more than one name. In other words,

386 Again, this phenomenon seems to be analogous to the empty pages at the end of multipletext codices. 
not every donor wrote their own name. ${ }^{387}$ Unfortunately, some of the inscriptions are unclear and thus it is difficult to compare the hands in the different cartouches. Nevertheless, as far as it can be seen, the main donor inscription and the inscriptions next to the figures of Zhigang, Miaozhen and Hezi appear to be in the same hand. This must have been the hand of Zhigang, one of the two main donors and possibly the eldest among the members of the Sun family.

The examples in Table 9 place the upper time limit of left-to-right inscriptions at 991, which is the date in the latest painting featuring an absolute date. As this is only 15 years away from the sealing of the Dunhuang library cave, it is possible that the practice did not discontinue but we simply do not have enough dated examples to document it beyond 991. It is noteworthy, however, that this date is a close match for the latest attested date of a manuscript featuring left-toright text (i.e. 990). Combining the evidence from the paintings and the manuscripts, that is, groups (ii) and (iii), we can establish that the practice of writing in this manner lasted from about 890 until 991 and possibly longer. The fact that the donor inscriptions in all paintings within this time frame read from left to right establishes a direct connection between the paintings and the practice of writing Chinese in a left-to-right direction. That is to say, the individuals who commissioned such paintings were those who invariably wrote their inscriptions in this way.

The list in Table 10 records paintings with dates given as cyclical signs. This list is shorter than the previous one as votive paintings tend to be dated unambiguously, for the date is an essential piece of information in donor inscriptions. According to the general time frame established in Table 9, the cyclical dates should fall between 890 and 991. In all but one case, it is in accord with how art historians have dated the items based on iconographic features.

387 This is, of course, self-evident in cases when deceased parents are also present among the donors. 
Tab. 10: Dunhuang paintings with cyclical dates.

\begin{tabular}{|c|c|c|c|c|}
\hline & Museum number & Central deity & Holding institution & Date \\
\hline 1 & Stein painting 32 & Bhaișajyaguru & British Museum & $\begin{array}{l}\text { bingchen } \\
(896 / 956)\end{array}$ \\
\hline 2 & MG 22799 & Guanyin & Musée Guimet & $\begin{array}{l}\text { jiashen } \\
(924 / 984)\end{array}$ \\
\hline 3 & MG 23079 & Amoghapāśa & Musée Guimet & $\begin{array}{l}\text { gengxu } \\
(890 / 950)\end{array}$ \\
\hline 4 & Stein 391 & Guanyin & National Museum, New Delhi & $\begin{array}{l}\text { jiashen } \\
(924 / 984)\end{array}$ \\
\hline 5 & Stein 357 & Guanyin & National Museum, New Delhi & $\begin{array}{l}\text { yimao } \\
(895 / 955)\end{array}$ \\
\hline 6 & P.4518 (27) & Vaiśravaṇa & $\begin{array}{l}\text { Bibliothèque nationale de } \\
\text { France }\end{array}$ & $\begin{array}{l}\text { tenth c., Year of } \\
\text { the Hare }\end{array}$ \\
\hline
\end{tabular}

Stein painting 32 is one of the largest paintings from Dunhuang $(152.3 \times 177.8 \mathrm{~cm})$ and has a Sino-Tibetan donor inscription that can only be seen via infra-red photography. Roderick Whitfield notes that this inscription runs from left to right and is dated to a bingchen 丙辰 year. He follows Heather Karmay in interpreting this as the year 836, towards the end of the Tibetan period. ${ }^{388}$ Karmay also notes that the name of the painter, identified in the Tibetan inscription as dPal-dbyangs, occurs in several manuscripts, unfortunately none of which are dated. Likewise, it is impossible to know whether it was the same dPal-dbyangs as the artist of the painting. ${ }^{389}$ Thus the assumption that the painting was produced during the Tibetan period seems to be based primarily on it having a Tibetan inscription and Tibetan stylistic elements. As we know now, however, Tibetan language and culture continued to have a strong presence in the region well into the Guiyijun period. As the Chinese inscription in Stein painting 32 is written in a leftto-right direction, the painting most likely dates from after 891, and thus the bingchen year should signify 896 or 956.

Progressing to other paintings in the group, MG 23079 from the Musee Guimet is dated to a gengxu 庚戌 (890/950) year, which, according to Michel Soymié who compared it with dated paintings, corresponds to $950 .^{390}$ The in-

388 Whitfield 1982-1985, 311-312. For an image of infra-red photograph of the very faded bilingual inscription, see ibid., v. 1, Fig. 43, as well as Wang 2018, 102.

389 Karmay 1975, 11-14.

390 Giès et al. 1994-1996, 348. 
scription identifies the figure in the picture as Bodhisattva Amoghapāśa (Bukong juansuo pusa 不空羅索菩薩) but writes the name phonetically as Bokong juansuo kusa 伯空卷索苦薩 (Fig. 56), exhibiting a complete disregard for the usual way of writing the name and the meaning of constituent characters. ${ }^{391}$ Apparently, whoever wrote the inscription in the cartouche thought of the name entirely phonetically. The date Soymie suggests is in full accord with our sample base of dated paintings in Table 9.

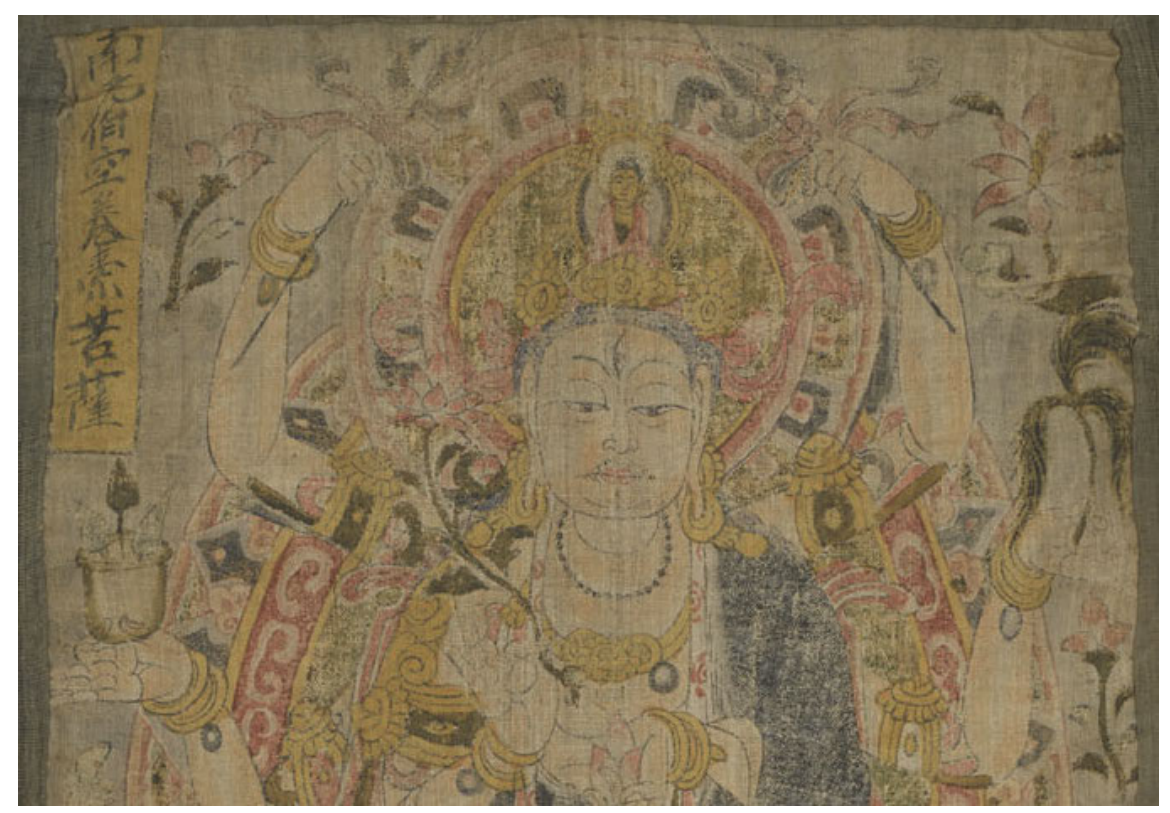

Fig. 56: Upper part of the figure of Amoghapāśa in MG 23079, with a phonetic rendering of his name in the cartouche. $(87.8 \times 50 \mathrm{~cm}$; courtesy of the Musée national des arts asiatiques Guimet)

Another painting in this group from the Musée Guimet is MG 22799, a long banner with two male and two female donors underneath a figure of Bodhisattva Guanyin. ${ }^{392}$ The caption in the catalogue identifies the banner as dating to the ninth year of the Taiping xingguo 太平興國 reign (984). ${ }^{393}$ In reality, the paint-

391 Soymié points out that while using the character 苦 instead of 菩 may be considered a banal mistake, writing 伯 for 不, and 卷 for 羂 is 'inexcusable'; see ibid.

392 On this painting, see also Soymié 1999, 13-14.

393 Giès et al. 1994-1996, 337-338. 
ing contains no reign title and Jean-Pierre Drège reads the date as the [...]shen $\square$ 申 year. He refers to the results of infra-red photography, which reveal that the previous character is jia 甲 and thus the date of the painting should be 984. ${ }^{394}$ As before, the date is in full agreement with the time range suggested by the presence of a left-to-right inscription.

P.4518 (27) is a painting on paper, showing an image of Vaiśravana. This is the only item in this group with inscriptions written in both directions. In addition to a horizontal Khotanese votive inscription dated to the Year of the Hare, the composition has two Chinese inscriptions, each running in an outward direction away from the central axis. ${ }^{395}$ Due to the presence of the Khotanese inscription, the Year of the Hare probably refers to 943 or $955 .{ }^{396}$ According to Fujieda Akira, the opposite directions of the two inscriptions are a matter of symmetric arrangement. ${ }^{397}$ The one on the left side of the upper part of the painting says 'Wholeheartedly offered to the Heavenly King by Wang Shangqing' 王上卿天王一心供養, in which the subject-object-verb sentence structure reflects the Khotanese word order. ${ }^{398}$ The name Wang Shangqing appears as Hvām’ Sām Khīnä in the Khotanese inscription at the bottom of the painting. While the name Shangqing 上卿 means 'senior minister' or just a high official in general, here it seems to work as a given name, which may be why the Khotanese text transliterates it.

Fig. 57 shows the lower half of the painting with the Khotanese votive text in the centre and a second Chinese inscription on the right, next to an image of a donor holding an incense burner. This is written in a much clumsier hand than the first one (not seen on the image here) and seems to read: 'Wholeheartedly offered by Zhang Ruzhe' 一心供飬張儒者. ${ }^{399}$ Although, once again, the word order is decidedly non-Chinese, there can be little doubt that it commemo-

394 Ibid. As a result of the same infra-red technology, Akiyama Terukazu reads the name of the elder brother as Wang Gebo 王擖撥. This name should be read Wang Laza 王擖韭; see below and especially the next chapter.

395 The Khotanese inscription was first published in Bailey 1956, 138; for a translation, see Dudbridge and Emmerick 1978, 283.

396 Dudbridge and Emmerick 1978, 284-285.

397 Ibid., 284.

398 The word order is, of course, exactly that of Tibetan as well.

399 Dudbridge and Emmerick (ibid.) note the problematic syntax of the two Chinese inscriptions and follow Fujieda Akira's suggestion that they must have been written by a non-Chinese, perhaps Khotanese, individual. The authors also point out (based on consultation with Fujieda Akira and Wu Chi-yu), the first character - ('one, whole') in the phrase yixin 一心 ('wholeheartedly') is overimposed on the character 發 ('to generate, depart'). The phrase faxin 發心 ('to generate the [enlightenment-]mind'), which is otherwise very common in Buddhist literature, does not work in this place. 
rates a votive act on the part of Zhang Ruzhe, who is also the donor depicted sitting on a mat, holding an incense burner. Even though the name Ruzhe means 'scholar', it almost certainly functions here as a given name. The name seems to point to a Chinese person, but the grammar and the inept handwriting do not corroborate this. Even without an explicit date, the Khotanese connection firmly places the painting in the tenth century, which also fits the time range of left-to-right inscriptions.

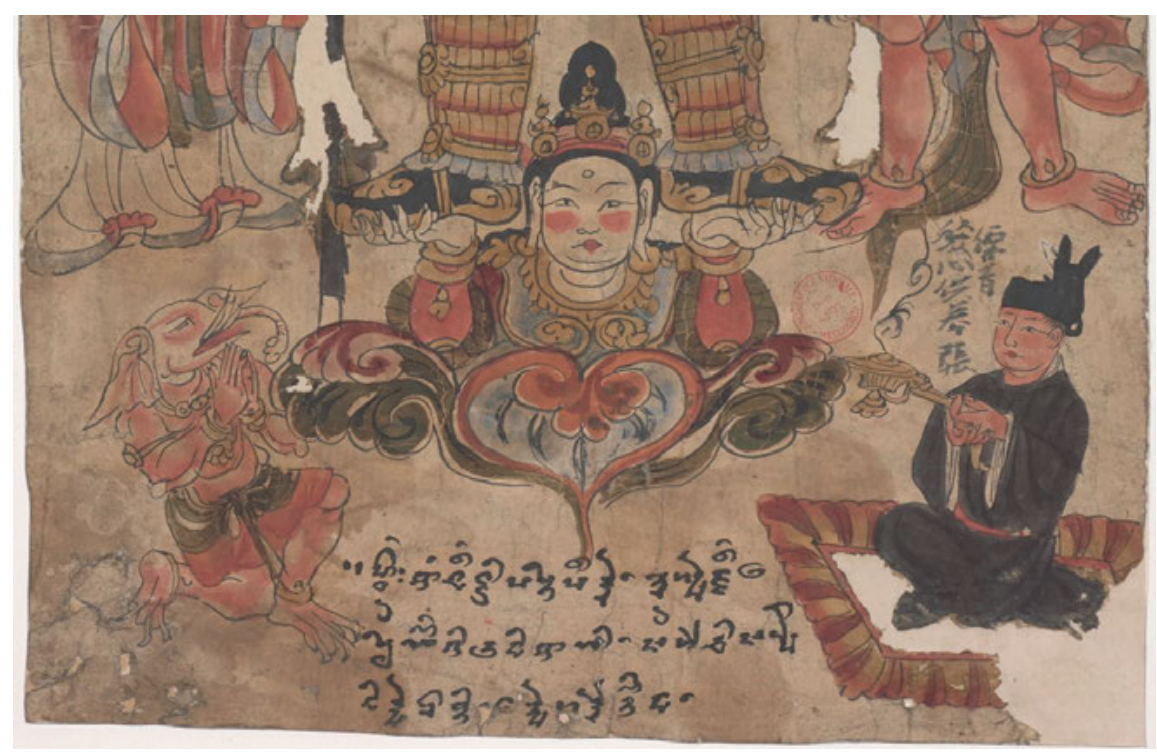

Fig. 57: Donor inscriptions in Chinese (right) and Khotanese (centre); detail from P.4518 (27). $(65.6 \times 34.5 \mathrm{~cm}$; Bibliothèque nationale de France)

Finally, Table 11 lists paintings in which the date is missing or illegible. The three paintings that are not in the list because their inscriptions read in the usual right-to-left direction are Stein painting 51/58; MG 17657; Stein painting 27 and Stein 356. These probably date to before the unorthodox direction became prevalent in votive inscriptions in Dunhuang. The first two items in Table 11 (Stein painting 3 and MG 23080) have inscriptions in both directions, which may suggest they are from the last third of the ninth century. 
Tab. 11: Dunhuang paintings with missing or illegible dates.

\begin{tabular}{|c|c|c|c|c|}
\hline & Museum number & Central deity & Holding institution & Date \\
\hline 1 & Stein painting 3 & Guanyin & British Museum & $\begin{array}{l}\text { last third of } \\
\text { ninth c.(?) }\end{array}$ \\
\hline 2 & MG 23080 & Guanyin & Musée Guimet & $\begin{array}{l}\text { last third of } \\
\text { ninth c.(?) }\end{array}$ \\
\hline 3 & P.4518 (19) & Guanyin & $\begin{array}{l}\text { Bibliothèque nationale de } \\
\text { France }\end{array}$ & after ca. 890 \\
\hline 4 & Stein painting 59 & Guanyin & British Museum & after ca. 890 \\
\hline 5 & Stein painting 63 & Guanyin & British Museum & after ca. 890 \\
\hline 6 & $\begin{array}{l}\text { Stein painting } 67- \\
68\end{array}$ & Śākyamuni Buddha & British Museum & after ca. 890 \\
\hline 7 & MG 17778 & Guanyin & Musée Guimet & after ca. 890 \\
\hline 8 & Stein painting 203 & Bhaișajyaguru & British Museum & after ca. 890 \\
\hline 9 & S.5666 & Rahu & British Library & after ca. 890 \\
\hline
\end{tabular}

Stein painting 3 has mirror images of Bodhisattva Guanyin, each accompanied by an inscription in which the vertical columns read from the central axis toward the outside. In this respect, the direction of writing seems to be part of the design and is thus predicated by the position of the lines in the composition. Such a symmetrical design, however, seems to have been an option only during the period when examples of left-to-right writing were in vogue. Former scholarship has dated this painting to the Tibetan period on the basis of interpreting the word luo 落 ('to fall') in the inscription as referring to the expression luofan 落番 ('fallen into the hands of the Tibetans'). ${ }^{400}$ Yet because the inscription is damaged, the character fan 番 ('Tibet') is purely conjecture. ${ }^{401}$ The relevant part of the inscription reads: '[This image of Guan]shiyin Bodhisattva was reverently made and wholeheartedly dedicated by the disciple of pure faith Wenyi in order

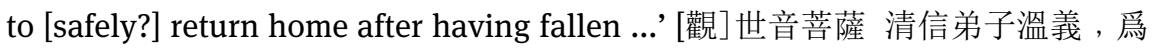

400 Whitfield 1982-1985, v. 1, 321-322 attributes this idea to a personal communication with Fujieda Akira, according to whom 'the character luo (fallen) seems in each case to invite completion with the character fan, as in other inscriptions in the caves themselves, referring to the Tibetan control of this district, and the principal wish is undoubtedly the very Chinese one of a desire to return home'. Cf. Wang 2018, 139.

401 Ma De 1996, 137 transcribes neither luo 落 nor fan 番, since the former is not clear, and the latter is altogether absent. 
己身落 $\square \square$ 歸鄉，敬造一心供養. ${ }^{402}$ The part allegedly referring to the Tibetans is missing in both inscriptions. Fortunately, a similar colophon is preserved at the end of manuscript S.2992, which contains a copy of the Guanyin jing. The colophon reads as follows:

\section{清信弟子女人賀三娘, 為落異鄉, 願平安, 申年五月廿三日寫。}

Copied on the twenty-third of the fifth moon of the shen year, to the order of the female Buddhist disciple of pure faith He Sanniang (i.e. 'third girl'), who, having fallen into a foreign land, prays for peace and happiness. ${ }^{403}$

Clearly, the 'foreign land' (yixiang 異鄉) mentioned in the colophon is not necessarily Tibet, at least not in the sense of a political entity. It certainly does not imply that Dunhuang was under alien control at the time. In a sense, it connects to the text of the scripture which urges people to call out to Guanyin in times of adversity, which includes finding themselves in inhospitable regions, such as the land of the rākșasa demons 羅刹鬼國. The expression 'having fallen into a foreign land', in pragmatic terms probably means she lived far away from home. Technically, the word yi 異 means 'different, other' and simply refers to living somewhere else.

Coming back to Stein painting 3, the inscription certainly expresses a desire to return home but there is no evidence of it being related to Dunhuang under Tibetan control. The word fan 番/蕃 is not in the painting but even if it once had been, it would not automatically prove a connection with the Tibetan period in Dunhuang. This information is insufficient to date the painting. Instead, the presence of inscriptions that read in opposing directions implies a date in the neighbourhood of 890 or slightly earlier, but definitely within the second half of the ninth century.

One of the possible explanations for the unconventional direction of writing in paintings is that the vertical lines move outwards from a central axis, which is often an image of the deity. Accordingly, the text emanates from the central image, as is commonly the case with flames or rays of light. Paintings do indeed exist with inscriptions running in opposite directions. Such an explanation has been noted in connection with painting P.4518 (27) above. Stein painting 3 presents a perfectly symmetrical layout in which the two facing inscriptions and

402 This bit is part of the right side inscription that reads from left to right. The other inscription is nearly identical, similarly missing the alleged reference to Tibet.

403 Translation loosely based on Giles 1957, 87. Giles tentatively dates the shen year (i.e. Year of the Monkey) to 768 . 
Guanyin figures are essentially mirror images of each other. A less regularised composition is Stein painting 14, in which the three cartouches with inscriptions appear on the two sides of a standing figure of Guanyin (dated 910). The one on the left reads in the normal way from right to left, representing an outward direction from the central figure of the bodhisattva. The two inscriptions on the other side, a larger one in a cartouche on the top right and a smaller one below, both read from left to right, similarly in a centrifugal direction. Thus, all three inscriptions proceed from the centre towards the outside. In the majority of paintings, however, the inscriptions do not follow this pattern of moving away from the centre. The most common type of votive inscription, almost always written from left to right, appears directly below the central image and thus its direction cannot be explained in terms of symmetry. Also, in most paintings all inscriptions read from left to right, making the symmetry hypothesis untenable.

The paintings demonstrate that the practice of writing inscriptions from left to right was directly connected to Guiyijun culture. The phenomenon begins around 890 and lasts until the end of the tenth century. The latest clearly dated example is from 991 but it is very likely that the practice continued beyond the time of the sealing of the library cave. Considering that this way of writing was otherwise rare, this was surely a local phenomenon connected to a specific group of people.

This group of people commissioned most of the surviving paintings on silk and canvas and also took an active role in the production of murals during this period. As votive inscriptions typically include the names of the donors, in many cases their identity is known. In terms of social hierarchy, they must have represented the elite echelons of Dunhuang society, with the financial means to commission potentially expensive votive objects. It is also noteworthy that many of the names are non-Chinese, even though the inscriptions and the manuscripts themselves are in most cases written in Chinese. A number of surnames are clearly associated with Sogdian background (e.g. Kang 康, Mi 米 or Shi 史).

As naming practices in the Guiyijun period will be the subject matter of the next chapter, here I only mention briefly the personal names evidencing the diverse cultural makeup of local society during the ninth and tenth centuries. For instance, the donor's name in Stein painting 19 (dated 963) is Kang Qingnu 康清奴 (Fig. 58). The surname reveals that he was of Sogdian background and his family originally came from Samarkand. His given name Qingnu means 'Servant of Purity' in which the second element $n u$ 奴 was a frequent part of given names, translating the Sogdian word $\beta n t k$ ('slave, servant'). As this is a typical theophoric structure, the word qing 清 ('purity') must have been a Chi- 
nese (possibly abbreviated) rendering of the name of an Iranian deity. On the painting, Kang Qingnu's deceased mother is identified as being from the Yin 陰 clan (usually considered Chinese), so the donor himself must have been Chinese on his mother's side.

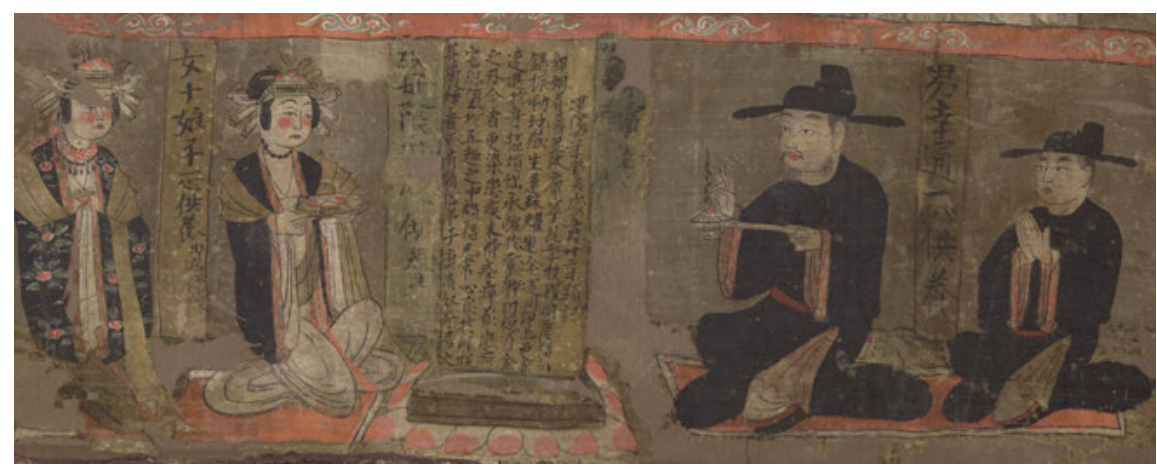

Fig. 58: Donors at the bottom of Stein painting 19, with a central votive inscription that reads from left to right. $(56.1 \times 51.5 \mathrm{~cm}$; The British Museum)

But donors also exist with Chinese surnames, as is the case with Stein painting 52, dated 971, the main donor of which is called Zhang Laza 張擖㩑, whose given name means 'heap of garbage'. ${ }^{404}$ This name was so unexpected that previous scholarship either misread it or marked it as illegible. ${ }^{405}$ Yet this was a relatively common given name that occurs in the Dunhuang manuscripts with different surnames. In the painting, the name of the mother is illegible, but Zhang Laza and his brothers' wives are from the Fan 氾 and Song 宋 families, with typically Chinese surnames. Zhang Laza's name also occurs in several circulars of irrigation channel managers (quren zhuantie 渠人轉帖) in manuscript P.5032, possibly referring to the same person. This is further supported by the fact that the manuscript mentions a number of individuals from the Zhang,

404 The opprobrious name Laza was not uncommon in Dunhuang and there are many examples in donor inscriptions and name lists attached to circulars. For the word laza, alternatively written as laza 拉雜 (and its various orthographic variants), see the detailed and instructive analysis in Mair 1999, 14-39.

405 Whitfield 1982-1985, v. 2, 320 reads the given name as Keqiao (sic., 擖橋?), whereas Ma De 1996, 139 uses empty squares to mark its illegibility. Whitfield is correct that the character 擖 indeed has a reading of $g e(<\mathrm{ke})$, yet in combination with the character 㩑 it should be read as ye or la. 
Fan and Song families, whose surnames match those of the primary donors in the painting. Yet the same manuscript also lists people with surnames such as Kang 康, An 安, Sun 孫, Qu 屈, Shi 石, Jia 賈 and Yin 陰, who have both a Central Asian and Chinese background. If anything, this situation evidences the complex makeup of Dunhuang society at the time, and that people of Chinese and Central Asian origin not only interacted in their daily business but also intermarried and formed mixed lineages. Their children, regardless of surname, integrated diverse linguistic and cultural elements.

\subsection{Conclusions}

Vertical columns written from left to right are merely one pattern observable in the layout of manuscripts and inscriptions in groups (ii) and (iii). It is also apparent, that these two groups belong to a very similar time frame. They are, however, different from the examples in mandalas and amulets, which unquestionably reflect a Tibetan influence. Although we can identify, especially in the paintings, occasional Tibetan elements, on the whole, groups (ii) and (iii) do not exhibit a consistent link with Tibetan scribal culture and art. When searching for potential sources of influence, the Uighur and Sogdian scripts are the only ones in the Hexi region that could be written vertically from left to right. ${ }^{406}$

As seen above, the paintings and the manuscripts include some surnames of Sogdian ancestry, but typical Chinese surnames may also be paired with given names that suggest a Central Asian influence. It is also important that the donor families in the paintings are often of mixed cultural heritage. This observation fits well with our understanding of the cultural and linguistic situation along the Silk Roads and it is likely that these families were both multilingual and multicultural. Directly equating the people who produced the left-to-right inscriptions with Sogdians is problematic as they had been in the region for centuries and one would need to explain the appearance of this new development within their own culture. As far as we know, there was no new wave of Sogdian immigrants around the end of the ninth century. ${ }^{407}$ There were, howev-

406 The Uighurs borrowed their script from the Sogdians and thus these two scripts are genetically related. The vertical orientation of the Old Uighur script continued when it was adapted to write the Mongolian and later the Manchu languages.

407 Early presence of Sogdians at Dunhuang is attested by the 'Sogdian ancient letters' found by Aurel Stein among the ruins of a watchtower west of Dunhuang. The letters date to the early fourth century and were written in Gansu; see Sims-Williams 1985 and de la Vaissière 2003, 24. For a translation of Letter II, see Sims-Williams 2001. 
er, large groups of Uighurs who moved southwards following the 840 collapse of the Uighur Empire to form independent states in Ganzhou and Xizhou, east and west of Dunhuang. Although the Uighurs were not present as a political entity in Dunhuang before the beginning of the eleventh century, ${ }^{408}$ the gradual formation of the Ganzhou Uighurs Khaganate from around 890 roughly coincides with the time when examples of left-to-right bits of writing in manuscripts and paintings from Dunhuang begin to appear. ${ }^{409}$ In Dunhuang, this is the point when the Zhang family struggles to maintain control and the region sinks into political turmoil.

Of course, the Dunhuang manuscripts and paintings in groups (ii) and (iii) are in Chinese and we are merely dealing with an influence from a different culture, whether Uighur, Sogdian or a mixture of both. The elite families who commissioned the votive paintings came to the foreground in this period, evidencing a new cultural and political identity. Accordingly, the culture of the elite reflected in the Guiyijun manuscripts and paintings is entirely different from the pre-Tibetan period when the region was still part of the Tang empire. With the end of the political dominance of Tibet, a new type of culture emerges with strong Central Asian elements. ${ }^{410}$ At the same time, Tibetan culture and language remained influential even though politically the region was no longer under Tibetan rule. Guiyijun Dunhuang developed a new type of culture that differed greatly from that in the Tang empire and labelling it 'Chinese' is an oversimplification, even if the community primarily wrote its manuscripts and inscriptions in Chinese. ${ }^{411}$ Clearly, the situation was far more complex. ${ }^{412}$

The early eleventh century, when the library cave was sealed, represents the cut-off date for the manuscripts and portable paintings. Fortunately, in addition to this material, there is an abundance of murals inside the Mogao

408 Moriyasu 2000, 33-34.

409 Sims-Williams and Hamilton 2015, 11-12 draw attention to the existence among the Dunhuang manuscripts of a small group of so-called Turco-Sogdian documents, which attest to the close contacts and intermixing of Sogdians and Uighurs.

410 Russell-Smith 2005 argues that a new local painting style developed in the tenth century, which supports the findings advanced in this paper, although the examples of text written from left to right indicate that this new local culture emerged at the end of the ninth century.

411 Kornicki 2018 convincingly argues that Sinitic, that is, the written form of Chinese, should be regarded as an East Asian script shared by a variety of cultures throughout East Asia. It is possible to argue that the Guiyijun period in Dunhuang was yet another example of a nonChinese culture that used the Chinese script.

412 See the arguments in Russell-Smith 2005, 227-231 for the emergence of a local culture, which was neither specifically pro-Chinese nor 'anti-foreign'. 
Caves, and some of these also contain inscriptions written from left to right. In contrast to the contents of the library cave, the time frame of the murals is not restricted by the sealing of the cave and so they preserve a sizeable body of art produced during the eleventh and twelfth centuries. In practical terms this means that they cover the rest of the Guiyijun period, undocumented in the contents of the library cave, as well as the period of Tangut control over Hexi. With time, however, following the move of China's economic and cultural centres to the south and the rise of the maritime Silk Road, Dunhuang lost its strategic location, which in turn led to the decline of Buddhist patronage and cavebuilding activity. ${ }^{413}$ The murals in the caves may help us arrive at a more accurate time frame for the left-to-right inscriptions at Dunhuang. Although many of the caves were rebuilt in later periods and some of the murals and inscriptions were painted over with new ones, there are extant murals and inscriptions from most periods prior to the Mongols. Regrettably, the mural inscriptions are less accessible, as reproductions tend to focus on pictorial material and the overall composition of the caves. Consequently, the reproductions often do not include all inscriptions, or their quality is such that it is difficult to read them. In most cases the inscriptions are available only in transcription with no mention of the direction of writing. ${ }^{414}$ Therefore, despite the potential benefits of such a study, the analysis of the direction of writing on mural inscriptions is a task yet to be undertaken.

The direction of writing in Dunhuang manuscripts and paintings may seem a technical matter, a pedantic attention to details of little consequence. Perhaps this is the reason why former scholarship has paid little attention to this phenomenon and very few attempts have been made to address the problem in any depth. Yet, as this chapter argues, a systematic examination of relevant examples reveals the influence of non-Chinese scribal cultures. Exploring the potential source of this practice has obvious implications for understanding the cultural background of the paintings and manuscripts and offers an independent criterion for dating them. Most importantly, we can appreciate the differences in comparison with the time when the region was still part of the Tang realm.

From a purely technical point of view, establishing the time frame for the left-to-right bits of writing allows us to date other manuscripts and paintings

413 Rong 2013, 76-77.

414 For example, the collection of donor inscriptions from the Mogao Caves merely notes in the introduction (Dunhuang yanjiuyuan 1986, 2) that some of the inscriptions read from left to right and others from right to left but gives no indication of the direction of writing for individual inscriptions. 
with greater accuracy. Naturally, this method should not be applied mechanically and, in each case, we should consider other types of evidence, if available. Nevertheless, the method itself is a step towards dating artefacts by means of quantifiable and objective data. As additional manuscripts and paintings are identified, it may become possible to refine the chronological framework of the practice, and thereby enhance our understanding of its social and cultural background. 